\title{
Gray whale migration patterns through the Southern California Bight from multi-year visual and acoustic monitoring
}

\author{
Regina A. Guazzo ${ }^{1,5, *}$, Alisa Schulman-Janiger ${ }^{2}$, Michael H. Smith ${ }^{3}$, Jay Barlow ${ }^{4}$, \\ Gerald L. D'Spain ${ }^{1}$, Dennis B. Rimington ${ }^{1}$, John A. Hildebrand ${ }^{1}$ \\ ${ }^{1}$ Scripps Institution of Oceanography, University of California San Diego, La Jolla, California 92093-0205, USA \\ ${ }^{2}$ Natural History Museum of Los Angeles County, Los Angeles, California 90007-4057, USA \\ ${ }^{3}$ Gray Whales Count, Santa Barbara, California 93109-1209, USA \\ ${ }^{4}$ National Oceanic and Atmospheric Administration, Southwest Fisheries Science Center, La Jolla, California 92037-1508, USA
}

${ }^{5}$ Present address: Naval Information Warfare Center Pacific, San Diego, California 92152-5001, USA

\begin{abstract}
Sightings and acoustic recordings from eastern North Pacific gray whales in the Southern California Bight were analyzed for interannual changes and compared with concurrent environmental measurements during 7 migration seasons (2008-2009 to 2014-2015). Acoustic call counts recorded on an offshore hydrophone were highly variable from year to year. Assuming an average calling rate of 7.5 calls whale $\mathrm{e}^{-1} \mathrm{~d}^{-1}$, the estimated number of whales migrating by this hydrophone would be $<10 \%$ of the population within $20 \mathrm{~km}$ of the offshore hydrophone in most years. In contrast, the estimated number of gray whales migrating off Santa Barbara and Los Angeles based on visual surveys grew at a greater rate $\left(11 \% \mathrm{yr}^{-1}\right.$ and $26 \% \mathrm{yr}^{-1}$, respectively) than the population size growth rate $\left(5 \% \mathrm{yr}^{-1}\right)$. Over the studied migration seasons it seems an increasing proportion of the population was using the nearshore migration corridor in the Southern California Bight, especially near Los Angeles. This trend could increase the negative anthropogenic impact on this species. Although several large-scale climatic events occurred between 2008 and 2015, neither water temperature in the Southern California Bight nor sea ice timing in the gray whale Arctic feeding area improved generalized additive models of gray whale nearshore sightings or offshore acoustic presence. Over these times, the gray whale migration timing appears to be driven more by their biological clock and instinct than by the extrinsic factors accounted for in the present analysis. Future work should test if other factors influence the gray whale migration over longer timescales.
\end{abstract}

KEY WORDS: Gray whale - Acoustic monitoring • Visual survey · Generalized additive model · Migration $\cdot$ Sea ice $\cdot$ Temperature $\cdot$ Southern California Bight

\section{INTRODUCTION}

Eastern North Pacific gray whales Eschrichtius robustus (Lilljeborg, 1861) annually migrate from the Arctic and subarctic waters of the Bering, Chukchi, and Beaufort Seas where they feed in the summer to

${ }^{*}$ Corresponding author: rguazzo@ucsd.edu the subtropical waters of the Pacific lagoons in the Baja California Peninsula, Mexico, where they spend the winter. Their migration path is along the continental shelf for most of the route, but in the Southern California Bight, many gray whales move offshore and travel through the Channel Islands (Carretta et

(C) The authors 2019. Open Access under Creative Commons by Attribution Licence. Use, distribution and reproduction are unrestricted. Authors and original publication must be credited. 
al. 2000, Sumich \& Show 2011). Gray whales are dependent on high-latitude, benthic-dominated ecosystems for feeding and low-latitude, warm lagoons for nursing calves and mating and, as a result, may be sensitive to environmental change and variation across their range.

Arctic amplification of climate change, or the greater temperature increase at high latitudes compared to low latitudes (e.g. Serreze et al. 2009), may impact gray whales. Gray whales primarily eat benthic, tube-dwelling amphipods, which had high population densities in the Chirikov Basin in the northern Bering Sea between at least the 19th-century whaling period and the 1980s (Highsmith \& Coyle 1991). Ampelisca macrocephala (Lilljeborg, 1852) is the dominant species in this area and in the gray whale diet (Rice \& Wolman 1971, Highsmith \& Coyle 1991). These amphipods live 5 to $6 \mathrm{yr}$, and females begin producing 1 brood $\mathrm{yr}^{-1}$ at 4 to $5 \mathrm{yr}$ old, so fewer, larger individuals make up most of the production (Highsmith \& Coyle 1991). The female amphipods brood their young and release juveniles directly into the adult habitat with no larval stage (Highsmith \& Coyle 1991). A. macrocephala primarily eat diatoms that sink from the phytoplankton bloom and also opportunistically consume larvae of sand dollars which compete for their habitat (Highsmith \& Coyle 1991). The number of eggs produced by a mature female is positively related to that female's size, which is negatively related to water temperature (Highsmith \& Coyle 1991). Therefore, warmer water temperatures could lead to smaller mature females producing fewer eggs. Ampelisca spp. biomass in the Chirikov Basin declined by almost $50 \%$ between the 1980s and 2002-2003 due to fewer large animals in the population (Coyle et al. 2007). Declines in amphipod biomass could have been due to top-down control by more gray whale predators as the population has recovered from over-exploitation, bottom-up control of sea ice timing affecting the organic carbon flux to the benthos (Coyle et al. 2007), and/or warmer water temperature reducing female amphipod size and fecundity (Highsmith \& Coyle 1991).

The Arctic sea ice decline is accelerating (e.g. Comiso 2012). The rate of sea ice decline from 19962010 was over twice as fast as the overall rate of decline from 1978-2010 (Comiso 2012). September, the middle of the gray whale summer feeding period, is the month with the least sea ice cover and the most dramatic decrease over this observation period (Comiso 2012). Although the rest of the Arctic is losing sea ice, the Bering Sea, through which gray whales travel and may feed, is gaining ice (Comiso
2012), possibly due to shorter timescale variation. A positive phase of the Arctic Oscillation (AO) index corresponds with increased sea ice in the Bering, southern Chukchi, and Beaufort Seas, while a positive phase of the El Niño Southern Oscillation (ENSO) index corresponds with decreased sea ice in the Chukchi and southern Beaufort Seas (Liu et al. 2004). Both of these climate oscillations occur on shorter timescales than the overall negative trend of Arctic sea ice (Liu et al. 2004).

A reduction in Arctic sea ice will likely result in an ecosystem shift. Sea ice cover influences the strength of pelago-benthic coupling and has resulted in highly productive benthic biomass regions (Piepenburg 2005). When sea ice lasts into spring, an early, ice-associated phytoplankton bloom quickly sinks and is available to benthic communities due to low zooplankton abundance (Overland \& Stabeno 2004). When sea ice melts earlier, the phytoplankton bloom occurs later when zooplankton are abundant and consume the bloom (Overland \& Stabeno 2004). Therefore, decreased sea ice may cause the Arctic to shift from a benthic-dominated ecosystem to a pelagicdominated ecosystem (Overland \& Stabeno 2004, Piepenburg 2005). Since the Arctic amphipods that gray whales eat have relatively long lifespans, their populations may not be as affected by interannual variations in sea ice, but more affected by long-term negative trends in sea ice and positive trends in temperature, which may reduce the number of individuals that survive to maturity, the body size of mature females, and the size of annual broods. Over time, decreased sea ice, warmer temperatures, and an Arctic ecosystem shift have the potential to negatively affect the amphipod population and therefore also the gray whale population if they are not able to switch to a different prey source.

Gray whale mortality may be linked to environmental change. In 1999 and 2000, many emaciated gray whales stranded along the west coast of North America in an unusual mortality event (Gulland et al. 2005). Around the same time, in the winters of 1998 and 1999, scientists counted the fewest numbers of female-calf pairs in the Mexico lagoons compared to other years with visual surveys (1978-1982, 19961999) (Urbán-Ramírez et al. 2003). It is unclear whether the unusual mortality event was due to the strong El Niño Southern Oscillation (ENSO) event, sea ice conditions, high population density of gray whales, or a combination of factors (Gulland et al. 2005). Coincidental with this mortality event, in the summers of 2000 and 2001, gray whale sightings around Kodiak Island, Alaska, were significantly 
higher than other years in a 5 yr aerial survey (Moore et al. 2007). The increased sightings in Alaska suggest that gray whales may have altered their migration and foraging pattern in response to a low food supply and opportunistically foraged along their migration route on lower-quality prey (Moore et al. 2007).

Gray whales may shift the timing and spatial distribution of their migration as a result of climatic change. The Pacific Decadal Oscillation (PDO) changed phases in the late 1970s from a negative phase to a positive phase (Mantua \& Hare 2002). Positive PDO phases are associated with warmer than normal temperatures along the North American Pacific coast and cooler than normal temperatures in the central North Pacific (Mantua \& Hare 2002). Concurrent with this phase change, the median date of the southbound migration shifted about a week later for sightings after 1987/1988 compared to those before 1980 (Rugh et al. 2001). This change in migration timing could be due to a decrease in benthic amphipod biomass in the gray whale foraging areas of the Chirikov Basin from the 1980s to 2000s causing the gray whale foraging range to expand north (Moore et al. 2003, Coyle et al. 2007). Currently, the central feeding area for the eastern North Pacific gray whales is in the Chukchi Sea along the continental shelf between Point Lay and Point Barrow, where their presence is correlated with high abundances of amphipods (Schonberg et al. 2014, Brower et al. 2017). If gray whales swim farther north to find suitable prey, they may also need to consume more calories to sustain their journey to and from the southern wintering areas.

Fecundity of gray whales is particularly affected by the availability of important feeding areas during the previous summer. More female-calf pairs are sighted in the lagoons and along the northbound migration route after summers with more ice-free days than after summers with fewer ice-free days, indicating that females may be less likely to carry their pregnancy to term or fewer calves may survive when the females have less time to feed during the previous summer (Perryman et al. 2002, Salvadeo et al. 2015). These studies measured interannual fluctuations in sea ice, but it is unknown how gray whales will be affected by long-term negative trends in sea ice, which may be more likely to affect the benthic amphipod biomass. Once gray whales reach Mexico, the oceanic conditions may dictate which lagoon females choose while nursing their calves. When the sea surface temperature was warmer during an El Niño, more females with calves were in the northern- most lagoon, but when the temperature was cooler during a La Niña, more females with calves were in the southernmost lagoon (Gardner \& Chávez-Rosales 2000, Salvadeo et al. 2015). Additionally, since 1980, sightings of southbound migrating calves as well as sightings of calves per gray whale have increased (Shelden et al. 2004). These observations have suggested a northward shift in birthing location that may be due to warmer temperatures and a shift in prey location forcing gray whales to travel farther north to feed, increasing the length of their migration and causing pregnant gray whales to give birth before they reach Mexico (Shelden et al. 2004). From these observations, PDO and ENSO climatic cycles as well as sea ice cover seem to affect the timing and distribution of the gray whale annual migration and the population health (including body condition, population growth rate, and population composition).

The gray whale migration has been monitored since the 1960s as the population has recovered from over-exploitation. Most monitoring has been in the form of shore-based visual surveys along their migration route. Long-term surveys have been conducted at Granite Canyon (e.g. Buckland et al. 1993, Durban et al. 2015), Piedras Blancas (e.g. Perryman et al. 2014), Santa Barbara (www.graywhalescount.org), and Point Vicente (https://acs-la.org/GWCensus. $\mathrm{htm})$, all in central and southern California. Aerial surveys have also been conducted over parts of the migration route, with surveys of the migration through the Southern California Bight in 1988-1990 (Sumich \& Show 2011) and 1998-1999 (Carretta et al. 2000). These aerial surveys have shown that in the Southern California Bight, some of the gray whale population maintains a coastal migration route within a few kilometers of the mainland, while the majority of the population migrates through the Channel Islands, primarily using routes around the western sides of Santa Catalina and San Clemente Islands (Sumich \& Show 2011). Around San Clemente Island, daily averages of $>400$ animals migrating in both directions were estimated between January and April in 1999 (Carretta et al. 2000). However, high interannual variability exists in the numbers of whales on each migration route (Sumich \& Show 2011), so population size estimation is challenging using data from sites in southern California alone.

Understanding the migration routes of gray whales through the Southern California Bight is important for quantifying the anthropogenic impact on this species. Along the coastal route, the San Pedro Bay port complex (ports of Los Angeles and Long Beach) is the ninth-busiest container port complex in the world 
(www.portoflosangeles.org/about/facts.asp), and Los Angeles is the second-largest metropolitan area in the United States. Gray whales that migrate along the coast may be vulnerable to ship strikes, fishing gear entanglements, increased background noise, and chemical pollution. A study on the western North Pacific population of gray whales showed that of 150 gray whales photographed, $20 \%$ had at least 1 visible anthropogenic scar (Bradford et al. 2009). Most of the scars were likely from fishing gear entanglements, but a few whales had scars that were likely from vessel collisions (Bradford et al. 2009). Entanglements and collisions may be fatal, so the proportions of scarred living whales underestimates the true number of gray whales that had negative anthropogenic interactions (Bradford et al. 2009). Low-frequency ambient noise levels along the shallow continental shelf may be affected by local shipping, while noise levels in deep water along the offshore route may be affected by both distant and local shipping, with waves and biological sounds adding to the soundscape in both locations (McDonald et al. 2006, 2008). Gray whales have been shown to change their behavior to avoid local noise sources (Malme et al. 1984, Weller et al. 2002), and studies with other cetacean species have shown that increased background noise from distant shipping may increase stress (Rolland et al. 2012) and cause whales to increase their call amplitude (Parks et al. 2010) or else decrease their communication range. Winter rain in southern California causes an influx of debris and chemical pollution into the ocean. Runoff plumes can spread 2 to $10 \mathrm{~m}$ deep, up to $10 \mathrm{~km}$ offshore and alongshore, and can persist multiple days (Bay et al. 1999). The spread of plumes depends on the amount of rain, but urbanized watersheds, especially those with concrete channels common in southern California, result in higher peak flows into the ocean and more toxic runoff than those from natural creeks and rivers (Bay et al. 1999). The effects of these rain events on large marine mammals are poorly understood, but sea urchin toxicity tests indicated that the runoff plume was toxic (due in a large part to zinc and copper levels) up to $3 \mathrm{~km}$ from the mouth of the channel (Bay et al. 1999). A better understanding of the proportion of the gray whale population taking each migration route through the Southern California Bight will help to increase our knowledge about the numbers of whales affected by various human activities.

Passive acoustic monitoring can be used to measure marine mammal presence in remote locations for many years with lower effort than visual surveys.
While migrating, gray whales primarily produce M3 calls (Cummings \& Thompson 1971, Crane \& Lashkari 1996). These calls are $1.8 \mathrm{~s}$ in duration with a weighted mean frequency of $48 \mathrm{~Hz}$ and a root mean square source level of $156.9 \mathrm{~dB}$ re $1 \mu \mathrm{Pa}$ at $1 \mathrm{~m}$ (Guazzo et al. 2017). Although calling rate seems to be variable between individuals and changes over diel and monthly timescales (Guazzo et al. 2017, in press), M3 calls have been recorded at the Granite Canyon site in central California from the beginning of December until the beginning of May, which spans the majority of the gray whale migration (Guazzo et al. 2017). Therefore, gray whale M3 calls can be used as an indicator of gray whale presence.

The eastern North Pacific population of gray whales contains 26960 individuals (2015-2016 NOAA census; Durban et al. 2017) and is no longer considered endangered under the US Endangered Species Act. However, it is uncertain how these migratory whales, which are so dependent on the Arctic benthos and Mexican lagoons, will respond to climate change. In addition to climate change, local anthropogenic activities can affect gray whales, and the scale of these effects on the gray whale population is unclear. To investigate the effects of climate on the annual variations in the migration and to better understand the gray whale migration through the Southern California Bight, we analyzed 7 migration seasons of acoustic data recorded north of San Clemente Island and of shore-based sightings from Los Angeles and Santa Barbara in southern California. This paper describes the timing, variability, and trends of the acoustic and visual records of the gray whale migration through the Southern California Bight and evaluates various signals that may influence the migration.

\section{MATERIALS AND METHODS}

\subsection{Data description}

\subsubsection{Passive acoustic call detections}

Single-hydrophone, high-frequency acoustic recording packages (HARPs) (Wiggins \& Hildebrand 2007) were deployed in the Southern California Bight at approximately $33.5^{\circ} \mathrm{N}$ and $119.25^{\circ} \mathrm{W}$ (Fig. 1) and recorded continuously. These bottom-moored devices were $\sim 900 \mathrm{~m}$ deep, $90 \mathrm{~km}$ southwest of Los Angeles and $80 \mathrm{~km}$ northwest of San Clemente Island. For this analysis, we used acoustic data from deployments during each gray whale Eschrichtius 


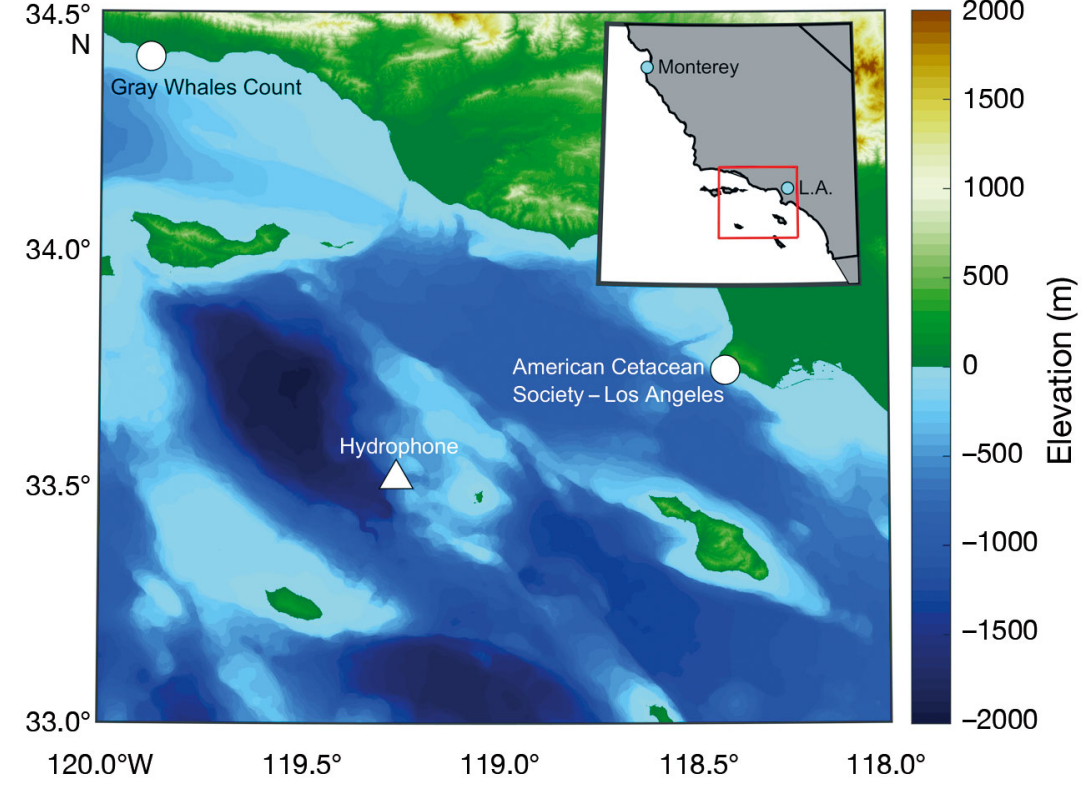

Fig. 1. Gray whale monitoring locations. The study area is in the Southern California Bight as denoted by the red box in the inset map. The NOAA Granite Canyon southbound gray whale census takes place just outside of Monterey in the inset map. The acoustic recording location is marked with a white triangle, and the visual survey locations are marked with white circles. For reference, Santa Barbara Island, the small island east of the hydrophone, is $\sim 20 \mathrm{~km}$ from the hydrophone. Variations in hydrophone deployment locations are too small to be seen on this map. Colors indicate land elevation and seafloor depth with respect to sea level (NOAA National Centers for Environmental Information's Southern California Coastal Relief Model, 3 arc-second resolution) fast Fourier transformed data (1024 sample FFT length, 95\% overlap). The detection spectrograms were then visually verified to be M3 calls by an experienced analyst (R.A.G.).

We used a similar procedure to that described by Helble et al. (2013) to estimate probability of detection for the HARPs and the variation of that probability with ocean noise levels. In brief, this Monte Carlo method simulated a random two-dimensional (2-D) distribution of whales around the hydrophone in various noise conditions and estimated the probability of detection as a function of ambient noise by utilizing estimated source levels and propagation loss modeling. However, instead of using CRAM, the C-code version of the 2-D Range-dependent Acoustic Model (RAM; Collins 1993) as was used in Helble et al. (2013), we used the 3-D Peregrine parabolic equation propagation model (Heaney \& Campbell 2016, Heaney et al. 2017). This model is based on RAM but has been extended to 3-D propagation that allows for diffraction and refraction robustus migration season between 2008-2009 and 2014-2015. Dates, positions, and seafloor depths for each deployment are listed in Table 1. The HARPs recorded with a sampling rate of $200 \mathrm{kHz}$, and we decimated the data to a sampling rate of $2 \mathrm{kHz}$ for an effective bandwidth of 10 to $1000 \mathrm{~Hz}$. A generalized power law (GPL) detector (Helble et al. 2012) with parameters optimized for gray whale M3 calls (Guazzo et al. 2017) identified potential calls in the around bathymetry (Heaney \& Campbell 2016, Heaney et al. 2017). In this paper, only the 2-D version of Peregrine was used, and 3-D propagation was modeled using an ' $\mathrm{N}$ by 2-D' approximation in which no coupling of acoustic energy occurs between the $\mathrm{N}$ radials in azimuth, as in Helble et al. (2013). The sediment thickness was $\sim 300 \mathrm{~m}$ at the HARP location (5 arcmin resolution; Whittaker et al. 2013), but a sediment thickness of $200 \mathrm{~m}$ was used in the Pere-

Table 1. Deployment locations of high-frequency acoustic recording packages. Dates are based on local time. Although each deployment was intended to be in the same location, there was some variability. Seafloor depths are in meters. Recording failed on: ${ }^{\mathrm{a}} 13$ Apr 2009-23 Apr 2009, b15 Feb 2010 for 9 h and 19 Feb 2010-22 Feb 2010, '3 Nov 2011-13 Nov 2011

\begin{tabular}{|lccrr|}
\hline Migration season & Dates & Latitude & \multicolumn{2}{c|}{ Longitude } \\
\hline $2008-2009$ & 13 Jan 2009-07 Mar 2009 & $33^{\circ} 30.582^{\prime} \mathrm{N}$ & $119^{\circ} 15.282^{\prime} \mathrm{W}$ & Depth \\
$2008-2009$ & 11 Mar 2009-03 May 2009 & $33^{\circ} 30.579^{\prime} \mathrm{N}$ & $119^{\circ} 15.280^{\prime} \mathrm{W}$ & 895 \\
$2009-2010$ & 05 Dec 2009-24 Jan 2010 & $33^{\circ} 30.937^{\prime} \mathrm{N}$ & $119^{\circ} 14.798^{\prime} \mathrm{W}$ & 912 \\
$2009-2010$ & 30 Jan 2010-24 Mar 2010 & $33^{\circ} 30.915^{\prime} \mathrm{N}$ & $119^{\circ} 14.690^{\prime} \mathrm{W}$ & 891 \\
$2010-2011$ & 06 Dec 2010-23 Apr 2011 & $33^{\circ} 30.897^{\prime} \mathrm{N}$ & $119^{\circ} 14.888^{\prime} \mathrm{W}$ & 919 \\
$2011-2012$ & 27 Oct 2011-17 Mar 2012 & $33^{\circ} 30.886^{\prime} \mathrm{N}$ & $119^{\circ} 14.869^{\prime} \mathrm{W}$ & 927 \\
$2012-2013$ & 20 Dec 2012-24 Apr 2013 & $33^{\circ} 30.599^{\prime} \mathrm{N}$ & $119^{\circ} 15.305^{\prime} \mathrm{W}$ & 907 \\
$2013-2014$ & 10 Sep 2013-06 Jan 2014 & $33^{\circ} 30.584^{\prime} \mathrm{N}$ & $119^{\circ} 15.252^{\prime} \mathrm{W}$ & 917 \\
$2013-2014$ & 06 Jan 2014-03 Apr 2014 & $33^{\circ} 30.577^{\prime} \mathrm{N}$ & $119^{\circ} 15.251^{\prime} \mathrm{W}$ & 877 \\
$2014-2015$ & 04 Nov 2014-01 Feb 2015 & $33^{\circ} 30.837^{\prime} \mathrm{N}$ & $119^{\circ} 14.943^{\prime} \mathrm{W}$ & 900 \\
\hline
\end{tabular}


grine model, which is valid since the longest wavelengths of gray whale calls are much less than the sediment thickness. The winter sound speed profile was created from an average of typical winter conditions. The sound speed at the surface was $\sim 1500 \mathrm{~m}$ $\mathrm{s}^{-1}$ and decreased to $1490 \mathrm{~m} \mathrm{~s}^{-1}$ at depths below $40 \mathrm{~m}$.

We then used a Monte Carlo method similar to that described by Helble et al. (2013) to insert a high signal-to-noise ratio (SNR) M3 call, which was assumed to have the characteristics of a source call, into 272 randomly selected, 75 s samples of background noise from the December 2012-April 2013 deployment, so that the inserted call never overlapped with disk write noise from the recording system. The RMS source level of the M3 call was $156.9 \mathrm{~dB}$ re $1 \mu \mathrm{Pa}$ at $1 \mathrm{~m}$, which was the mean measured by Guazzo et al. (2017). Although source levels have some variance (11.4 dB as measured by Guazzo et al. 2017), we used the mean source level to calculate the probability of detection. We used the Peregrine propagation model to calculate the normalized complex pressure of a call as a function of frequency and modeled calls received by the HARP from source depths of $10 \mathrm{~m}$ (a reasonable swimming depth assumption for migrating gray whales, e.g. Sumich 2014), azimuth increments of $5^{\circ}$, and ranges out to $50 \mathrm{~km}$ (450 $\mathrm{m}$ increments). We inserted the propagated M3 calls into real HARP noise and then processed these new audio files with the GPL detector. We analyzed the proportion of these calls detected as a function of range, integrated over azimuth, to determine the probability of detection as a function of range. Probability of detection of gray whale M3 calls was approximately zero at ranges beyond $20 \mathrm{~km}$, so we assume a search area radius of $20 \mathrm{~km}$, and all probability of detection versus noise level values are for this search area. Since we could not determine the location of the calling animal with a single hydrophone and limit the search area, we had to use an integrated probability of detection over all possible ranges and azimuths as a function of all noise levels. We averaged the probability of detection across this search area for each noise sample. Even though multiple noise samples may have similar RMS noise levels, the probability of detection contains variance based on the source of the noise, which causes the M3 call to be more or less likely to be detected.

A power model $\left(y=a x^{b}\right)$ was fit to the Monte Carlogenerated samples of probability of detection as a function of root mean square (RMS) noise level integrated over the $20-100 \mathrm{~Hz}$ band, the same frequency band used for the GPL detections (Fig. 2), to estimate probability of detection of M3 calls across all noise levels. Physical constraints were applied in this

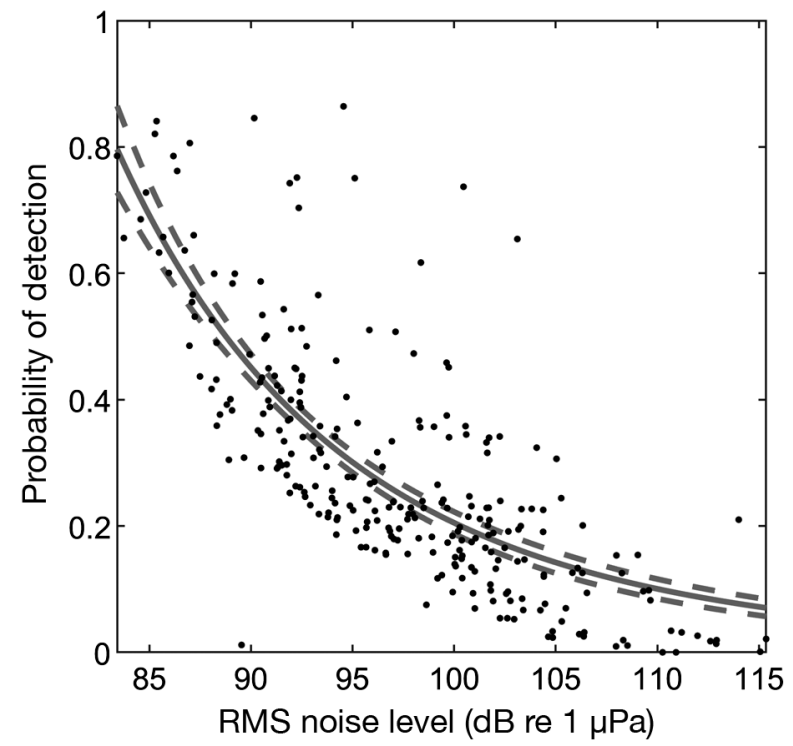

Fig. 2. Monte Carlo-generated samples of probability of detection versus noise level within a $20 \mathrm{~km}$ radius search area; 272 noise samples that were $75 \mathrm{~s}$ in duration were randomly selected from the December 2012-April 2013 deployment. Noise level was integrated over the 20-100 Hz band. The $y$-axis represents the proportion of source locations within a $20 \mathrm{~km}$ range at which an M3 call generated was successfully detected by the generalized power law (GPL) detector. A power model was fit to these data points. Dashed lines: 95\% prediction intervals (non-simultaneous functional bounds)

curve-fitting process. For example, based on the Peregrine model, the maximum transmission loss over the $20 \mathrm{~km}$ range is $\sim 90 \mathrm{~dB}$. From the passive sonar equation, the signal to noise ratio is:

$$
\mathrm{SNR}_{\mathrm{dB}}=\mathrm{SL}_{\mathrm{dB}}-\mathrm{TL}_{\mathrm{dB}}-\mathrm{NL}_{\mathrm{dB}}
$$

where SL is source level ( $\mathrm{dB}$ re $1 \mu \mathrm{Pa}$ at $1 \mathrm{~m})$, TL is transmission loss $(\mathrm{dB}$, received level at range $r$ relative to received level at $1 \mathrm{~m}$ ), and NL is noise level in the frequency band of interest ( $\mathrm{dB}$ re $1 \mu \mathrm{Pa}$ over $20-$ $100 \mathrm{~Hz}$ in this case). The SNR cannot be greater than zero, and as a result, probability of detection cannot equal 1 over this search area unless the noise level is less than $\sim 67 \mathrm{~dB}$ re $1 \mu \mathrm{Pa}$ for assumed source levels of $156.9 \mathrm{~dB}$ re $1 \mu \mathrm{Pa}$ at $1 \mathrm{~m}$ and a transmission loss from a $20 \mathrm{~km}$ range of $90 \mathrm{~dB}$. Noise levels in these recordings are $\sim 85 \mathrm{~dB}$ re $1 \mu \mathrm{Pa}$ or greater, so the probability of detection should never equal 1 in these recordings. Using the power model allowed for the best fit to the Monte Carlo data while predicting reasonable probabilities of detection based on these types of physical constraints. The prediction intervals of the power model show the $95 \%$ non-simultaneous (pointwise) functional bounds, so these bounds indicate the $95 \%$ 
confidence interval (CI) of the mean probability of detection at each noise level.

To estimate the number of calls produced within the $20 \mathrm{~km}$ search radius, we corrected the number of calls detected for the probability of detection in $75 \mathrm{~s}$ time bins. The RMS noise level was calculated for every $75 \mathrm{~s}$ period of recording and was used to estimate probability of detection during that time period. Numbers of M3 calls detected in each $75 \mathrm{~s}$ period were divided by the estimated probability of detection for the measured noise level from the power model fit to the Monte Carlo-generated samples. This correction for probability of detection resulted in an estimated number of calls produced in that $75 \mathrm{~s}$ period within the $20 \mathrm{~km}$ search radius. Peregrine and other parabolic models do not accurately predict transmission loss at ranges very near the source. Therefore, the Monte Carlo method may have not accurately predicted the probability of detection for calls produced within one water depth of the hydrophone. For these situations, simple spherical spreading was used. For example, a call produced by a whale directly overhead of the hydrophone would undergo the minimum transmission loss as it traveled from the whale to the hydrophone. Since the whale is assumed to be at $10 \mathrm{~m}$ depth and the hydrophone is at $\sim 900 \mathrm{~m}$ depth, the total distance the sound travels is $890 \mathrm{~m}$. Based on spherical spreading, the transmission loss is $59 \mathrm{~dB}$ (equal to 20log[900 - 10]). Assuming a source level approximately equal to the mean source level, time periods with noise levels $>100 \mathrm{~dB}$ re $1 \mu \mathrm{Pa}$ would have a probability of detection equal to zero. In addition, greater noise levels have small probabilities of detection which, due to dividing the number of detected calls by the probability of detection, lead to more uncertainty in the estimated number of calls. Therefore, all times with noise levels > $100 \mathrm{~dB}$ re $1 \mu \mathrm{Pa}$ were excluded from analysis (effort was zero), and daily counts were adjusted for total time without effort. Finally, to account for periods of HARP disk write noise, effort was zero for $7 \mathrm{~s}$ out of every $75 \mathrm{~s}$ during time periods when the RMS noise level was less than the threshold. Estimated total number of M3 calls for each day was then:

$$
\hat{N}_{\mathrm{C}}(t)=\sum_{j}\left[\frac{n_{\mathrm{c}}\left(t_{j}\right)}{\hat{P}_{\mathrm{D}}\left(t_{j}\right)}\right] \frac{1}{\left[1-P_{\mathrm{NE}}(t)\right]}
$$

where $j$ is an index for $75 \mathrm{~s}$ periods with noise levels $\leq 100 \mathrm{~dB}$ re $1 \mu \mathrm{Pa}, n_{\mathrm{c}}\left(t_{j}\right)$ is the number of detected calls in each $75 \mathrm{~s}$ period, $\hat{P}_{D}\left(t_{j}\right)$ is the estimated probability of detection in that $75 \mathrm{~s}$ period, and $P_{\mathrm{NE}}$ is the proportion of time in a day with no effort. Probability of false positives was assumed to be zero since all calls were manually verified to be gray whale M3 calls; however, if any calls were detected from outside of the $20 \mathrm{~km}$ search area, these calls would represent false positives.

Alternatively, acoustic hourly presence or absence can be used to quantify calling periods and is less influenced by changes in calling rate than total estimated calls. Using a metric that is robust to variable calling rate is important because Guazzo et al. (in press) showed that gray whale calling rate changes substantially over a migration season. Presence or absence of gray whale M3 calls for every hour and day of recording was saved together with the mean probability of detection during that hour and day.

\subsubsection{Sightings}

Shore-based visual surveys were completed annually by 2 organizations in southern California (Fig. 1). The American Cetacean Society - Los Angeles Chapter Gray Whale Census and Behavior Project (ACS/LA census) is located on the Palos Verdes Peninsula in Los Angeles County, California $\left(33^{\circ} 44.688^{\prime} \mathrm{N}\right.$, $118^{\circ} 42.709^{\prime} \mathrm{W}$ ), $41.8 \mathrm{~m}$ above sea level. Gray Whales Count (GWC) is located on Counter Point (or Coal Oil Point) part of the University of California Natural Reserve System in Santa Barbara County, California ( $\left.34^{\circ} 24.432^{\prime} \mathrm{N}, 119^{\circ} 52.701^{\prime} \mathrm{W}\right), 14.2 \mathrm{~m}$ above sea level.

ACS/LA census observers counted both southbound and northbound gray whales from 1 December until the middle or end of May for $\sim 12 \mathrm{~h}$ each day, sunrise to sunset (up to 18:00 h). Observers scanned with their naked eye and with $7 \times 50$ binoculars with built-in reticles and a compass, used to note distance and azimuth to each sighting. They also used spotting scopes to scan for distant sightings and to confirm species, counts, and presence of calves for all sightings. Whales from the coast to $\sim 8.6 \mathrm{~km}$ were tracked over a $145^{\circ}$ field of view. An observer was assigned to track each group as it traveled through the search area. Each sighting was updated 3 times: when the group was first seen, when it crossed directly in front of the observers $\left(220^{\circ}\right.$ azimuth), and when it left the field of view. This tracking helped to avoid double counting by ensuring a group did not turn around. Gray whales were included in the migration count when they passed the $220^{\circ}$ azimuth. Total number of whales as well as number of hours of active search (hours 'on-effort') were reported for each day. Single whales were differentiated from female-calf pairs. Direction of travel was noted, and 
calves were seen migrating in both directions. If the direction of a gray whale could not be determined, that whale was not included in either the southbound or northbound counts. Behaviors, sighting cues, unusual appearance, and interactions between gray whales and humans or other species were documented. Visibility and sea conditions (including Beaufort Sea State) were recorded at least every $30 \mathrm{~min}$. Visual observations continued regardless of environmental conditions (however, some days ended early due to poor conditions), and all times with observations were on-effort. During each watch period, a minimum of 2 and a maximum of 6 observers, including the project coordinator (A.S.J.) or a seasoned observer, were on-effort. Watch shifts lasted for 3 to $4 \mathrm{~h}$ to avoid observer fatigue. The project coordinator or a seasoned observer served as the watch anchor and recorded sightings for $\sim 6 \mathrm{~h} \mathrm{~d}^{-1}$, but took breaks as needed to avoid fatigue.

GWC observers recorded sightings of all northbound gray whales from the beginning of February until the end of May from 09:00 to 17:00 h daily. Similar to the ACS/LA census, observers scanned for whales with their naked eye and $7 \times 50$ binoculars with built-in reticles and a compass, used to note distance and azimuth to each sighting. A spotting scope was used to verify species. Whales from the coast to $\sim 5.6 \mathrm{~km}$ were observed over a $200^{\circ}$ field of view, but whales were not counted until they were between the $120-190^{\circ}$ azimuths for Phase A of the migration (northbound whales primarily without calves) and between the 80-190 azimuths for Phase $\mathrm{B}$ of the migration (northbound presumably female whales with calves). An observer was assigned to track each group of gray whales through the field of view. In this way, double counting was avoided, and group sizes were verified and updated. The total number of northbound whales as well as number of hours on-effort were reported for each day. Single northbound whales were differentiated from femalecalf pairs. In addition to marine mammals, vessel sightings were recorded along with any interactions between the vessel and animals. Weather was reported for each sighting and if the weather changed between sightings. Only times without rain and with adequate visibility $(>3.2 \mathrm{~km})$ and sea conditions ( $<5$ Beaufort Sea State) were included as on-effort. During each watch period, a minimum of 2 and a maximum of 5 observers, including the project coordinator (M.H.S.), were on-effort. Most observers worked $2 \mathrm{~h}$ shifts, but experienced observers sometimes worked $4 \mathrm{~h}$ shifts. These shift schedules helped to prevent observer fatigue. The project coordinator or another supervisor was always onsite to oversee the counting effort.

To estimate daily ( $24 \mathrm{~h}$ ) numbers of whales at each site and assess the patterns in each year's data, gray whale daily counts were divided by the proportion of the day on-effort:

$$
\hat{N}_{\mathrm{W}}(t)=n_{\mathrm{W}}(t) \frac{1}{\left[1-P_{\mathrm{NE}}(t)\right]}
$$

where $\hat{N}_{\mathrm{W}}(t)$ is the estimated number of whales each day, $n_{\mathrm{w}}(t)$ is the number of whales sighted that day, and $P_{\mathrm{NE}}(t)$ is the proportion of the day off-effort. Probability of false positives was assumed to be zero since all sightings counted were verified to be gray whales. Because perfect detection during on-effort times is unrealistic, all visual daily counts of whales are minimum counts. GWC annual northbound counts were separately corrected to account for probability of detection in the same way as described by Durban et al. (2015). These corrections result in annual estimates of the number of single gray whales and femalecalf pairs that migrated past Santa Barbara. The annual modeled counts were used to analyze interannual changes in numbers of whales, which is described further in Section 2.2.1.

In addition to these southern California survey efforts, we incorporated population abundance estimates from the National Oceanic and Atmospheric Administration's (NOAA's) Granite Canyon gray whale census. These estimates have been published by Durban et al. $(2015,2017)$. In this way, we were able to compare count trends at each southern California site with the overall population trends. These methods are described further in Section 2.2.1.

\subsubsection{Environmental measurements}

Satellites use microwave radiation to measure the percent of a given area covered by sea ice. The Advanced Microwave Scanning Radiometer (AMSR) instruments sense microwave emission from Earth's surface and are not affected by cloud cover (Kawanishi et al. 2003). Daily measurements of $89 \mathrm{GHz}$ center frequency were converted into sea ice concentration using the ARTIST Sea Ice (ASI) algorithm with $6.25 \mathrm{~km}$ grid resolution (Spreen et al. 2008). The AMSR-E instrument transmitted data from May 2002-October 2011, and the AMSR-2 instrument has been transmitting data since May 2012.

To calculate mean daily sea ice concentrations over the gray whale feeding area, we used software designed to visualize and summarize satellite data: 
Windows Image Manager (WIM) and WIM Automation Module (WAM) (Kahru 2001). We averaged the daily sea ice concentrations over the feeding area from Dease Inlet, east of Point Barrow, to Cape Lisburne covering the area from $\sim 20$ to $120 \mathrm{~km}$ from shore. This area was chosen based on gray whale aerial sighting data reported by Brower et al. (2017). We estimated the melt date as the last date in the spring when the average sea ice concentration dropped below a given threshold and the ice-over date as the first date in the fall when the average sea ice concentration across the feeding area increased above another threshold. Three different thresholds for melt date and ice-over date were used to test the sensitivity of the model to the amount of ice since it is uncertain at what point the gray whales would enter the feeding area or decide it is time to migrate south. The 3 thresholds used were $10 \%, 50 \%$, and $90 \%$. The length of the ice-free season was:

$$
L_{\mathrm{IF}}=D_{\mathrm{F}}-D_{\mathrm{M}}
$$

where $D_{\mathrm{F}}$ is the calendar date of the fall freeze, and $D_{\mathrm{M}}$ is the calendar date of the spring melt. We hypothesized that the timing of the fall ice-over would signal to the gray whales to start their southbound migration and that the length of the ice-free season would impact migration timing if the whales feed for a certain amount of time before migrating south again. The freeze and melt dates are not necessarily cut-offs for gray whale feeding; instead, they are markers for the spring melt and fall freeze. We tested all combinations of the melt and ice-over thresholds when defining the length of the ice-free season.

The California Cooperative Oceanic Fisheries Investigations (CalCOFI) collect oceanographic measurements and samples on quarterly cruises along transects that are perpendicular to the coast (https://calcofi.org). We averaged the temperatures of the upper $10 \mathrm{~m}$ of the water column from the winter cruises in mid-January to early February 2009-2015 to estimate temperatures that gray whales experienced while migrating. 'Offshore' temperature was measured $<10 \mathrm{~km}$ from the hydrophone at Stn $86.7 / 45\left(33.48953^{\circ} \mathrm{N}, 119.31910^{\circ} \mathrm{W}\right)$, 'nearshore' temperature was measured along the northern edge of the Palos Verdes Peninsula at Stn 86.7/33 $\left(33.88953^{\circ} \mathrm{N}, 118.49033^{\circ} \mathrm{W}\right)$, and 'Point Conception' temperature was measured at $\operatorname{Stn} 80 / 50.5\left(34.46667^{\circ} \mathrm{N}\right.$, $\left.120.48906^{\circ} \mathrm{W}\right)\left(\mathrm{Stn} 80 / 51.0\right.$ at $34.45000^{\circ} \mathrm{N}, 120.52390^{\circ} \mathrm{W}$ for the 2015 cruise), where southbound migrating gray whales likely select either an offshore route through the Channel Islands or a nearshore route. No temperature measurements were available at or near Point Conception in 2014. We hypothesized that gray whales use temperature along their migration route as a cue for navigation and timing.

\subsection{Analysis description}

\subsubsection{Interannual comparison}

To test if the same proportion of gray whales use the different southern California migration routes each year, we compared the growth rate observed at sites in southern California with that estimated from NOAA's gray whale population census. If a constant proportion of gray whales was using the nearshore route, the growth rate of estimated nearshore whales should equal the population size growth rate. However, if the proportion of gray whales using the nearshore route was increasing or decreasing over time, the growth rate of nearshore whales would be greater than or less than the population growth rate, respectively.

The eastern North Pacific gray whale population size was estimated by NOAA 3 times over this study period (Durban et al. 2015, 2017). Observers counted southbound migrating gray whales at Granite Canyon in central California in 2009-2010, 2010-2011, and 2014-2015. Although the 2015-2016 migration season was not included in our Southern California Bight analysis, we included this year in our population trend estimate in addition to the other 3 seasons to increase the sample size and precision of the trend due to lower precision of the 2014-2015 estimate. Counts of southbound gray whales were converted into estimated population sizes based on probability of detection and effort parameters (Durban et al. 2015).

We fit the population size and Southern California Bight observations with an exponential model:

$$
\begin{gathered}
d N / d t=r N \\
N=N_{0} \mathrm{e}^{r t}
\end{gathered}
$$

where $N$ is the annual counts, $r$ is the annual growth rate, $t$ is time in year, and $N_{0}$ is the count for the start of the time series. To test if the differences between growth rates were significant, we used analysis of covariance (ANCOVA) of the linear form of the exponential model:

$$
\ln N=r t+C
$$

where $C$ is $\ln \left(N_{0}\right)$.

Annual counts of gray whale M3 calls and ACS/LA sightings were calculated from the same days across all years so that a change in number was not due to ef- 
fort. The days were chosen based on the first and last dates that all years had in common. The number of calls during recording gaps within these dates was estimated using shape-preserving piece-wise cubic interpolation (piecewise cubic Hermite interpolating polynomial, pchip in MATLAB), which results in a smooth, continuous function that does not overshoot the data points (Fritsch \& Carlson 1980). Raw daily gray whale ACS/LA census sightings were corrected by dividing the counts by the proportion of the day on-effort (Eq. 3), and acoustic call counts were corrected by dividing by both the proportion of the day on-effort and the probability of detection (Eq. 2). Confidence intervals for estimated number of calls were estimated using the $95 \%$ non-simultaneous, functional prediction interval bounds for the noise level versus probability of detection Monte Carlo-generated data. Annual sightings of gray whales off Santa Barbara (GWC) were corrected for probability of detection using the model described by Durban et al. (2015). This model corrects for probability of detection, primarily influenced by visibility and number of whales passing at a time, and makes assumptions about the number of whales passing during off-effort times.

Acoustic calling rate may be more variable between years than cues used to recognize gray whales visually, like whale exhalations or 'blows'. It is unknown if or how gray whale calling rate changes between migration seasons, but humpback whales migrating off the coast of Australia have decreased their singing rate as their population size has increased (Noad et al. 2017). Gray whale calling rate was estimated by Guazzo et al. (in press) to be 7.5 calls whale $\mathrm{e}^{-1} \mathrm{~d}^{-1}$ at Granite Canyon averaged over the 2014-2015 migration season. If we assume this calling rate for all years, we can estimate the number of gray whales $\hat{N}_{\text {W }}$ that migrated within a $20 \mathrm{~km}$ radius of the hydrophone.

$$
\hat{N}_{\mathrm{W}}=\frac{\hat{N}_{\mathrm{C}}}{\hat{r}_{\mathrm{C}} \hat{t}_{\mathrm{SA}}}
$$

where $\hat{N}_{\mathrm{C}}$ is the estimated number of calls (from Eq. 2), $\hat{r}_{C}$ is the estimated calling rate, and $\hat{t}_{\mathrm{SA}}$ is the estimated average amount of time spent in the search area which was the average distance through the search area divided by the mean swim speed. Using the Mean Value Theorem, the average distance through search area is:

$$
\frac{\int_{0}^{2 \pi} 2 R \sin \frac{\theta}{2} d \theta}{2 \pi}
$$

which is $80 / \pi \mathrm{km}$ for a range from the hydrophone $R$, of $20 \mathrm{~km}$. Acoustically tracked gray whales migrate with an average speed of $1.6 \mathrm{~m} \mathrm{~s}^{-1}$ (Guazzo et al. 2017), so we estimate that migrating whales spent on average $\sim 4.4 \mathrm{~h}$ within the detection range of the hydrophone.

Finally, we compared observed changes in sea ice melt and freeze timing in the gray whale feeding area and changes in ocean temperature in southern California with known climate patterns observed over the same time.

\subsubsection{Generalized additive model regression analysis}

We hypothesized that interannual changes in sea ice in the Arctic feeding areas and local water temperature along the gray whale migration route would affect the gray whale migration through the Southern California Bight, compared to the null hypothesis that these environmental variables would not affect the gray whale migration. To test the alternative hypothesis, we used generalized additive models (GAMs; Hastie \& Tibshirani 1990) which model a link function (Table 2) of the response variable $(y)$ as the sum of non-linear functions $(f)$ of the predictor variables $(x)$ :

$$
\operatorname{link}\left(y_{i}\right)=\alpha+\sum_{j} f_{j}\left(x_{j}\right)+\epsilon_{i}
$$

where $i$ is the number of response variables, $j$ is the number of predictor variables for that response variable, $\alpha$ is a constant, and $\varepsilon$ is an error term. We used the R GAM package 'mgcv' with gamma $=1.4$ to avoid over-fitting (Wood 2006) and quantitatively evaluated potential models with Akaike's information criterion (AIC).

Table 2. Response variables used in generalized additive models. In the link function, log refers to natural log (or $\ln$ )

\begin{tabular}{|lccc|}
\hline Method & Variable & Family & Link function \\
\hline Acoustic M3 call detections & Hourly or daily presence & Binomial & Logit: $\log \frac{\mu}{1-\mu}$ \\
Gray whale sightings & Daily count & Poisson & Log: $\log \mu$ \\
\hline
\end{tabular}


Acoustic M3 call hourly and daily presence as well as visual daily gray whale counts were tested as response variables (Table 2). These response variables were tested over the full migration season as well as over the southbound and northbound migration phases separately in case the predictor variables impacted one phase of the migration more than the other. Since migration direction cannot be determined from single hydrophone acoustic data, gray whale acoustic presence models tested predictor variable effects on the full migration season, the first half of the migration (mostly southbound migrators), and the second half of the migration (mostly northbound migrators, acoustic data not available for 2014-2015). The ACS/LA census was used to determine the change from southbound to northbound because it is the only survey that monitors for the full duration of both phases of the migration. The starting date of the second half of the migration was defined as the first date that the northbound ACS/LA count exceeded the southbound count for this day and the day after. Models with visual daily counts as the response variable were fit separately for the 2 different sighting efforts (ACS/LA and GWC). The ACS/LA census monitored both the southbound and northbound migrations, so GAMs tested predictor variable effects on the full migration, southbound whales, northbound whales, and northbound calves. The GWC survey only monitored the northbound migration, so GAMs tested predictor variable effects on the full northbound migration, northbound single adults, and northbound calf counts.

Several predictor variables were chosen that we hypothesized may influence observations of the gray whale migration (Table 3). The null hypothesis was that the environmental variables did not affect the gray whale migration; therefore, models were compared with and without environmental variables. The non-environmental variables were temporal (year, day, hour, time of day) or were due to the limitations of the monitoring systems (probability of detection or effort). One null hypothesis tested if there was an interaction effect between year and day by including year $\times$ day instead of year and day separately. If the model with year $x$ day had a lower AIC than including these terms separately, it would suggest that the gray whale migration changes its timing with year. The acoustic response variables (hourly or daily presences) were not directly corrected for probability of detection because the form of that relationship is not known. Instead, acoustic probability of detection was treated as a potentially non-linear predictor of presence. In contrast, visual effort (proportion of the day searching) was treated as a linear offset of the log of effort since effort should be proportional to number of whales. Environmental variables included water temperature near the monitoring locations, water temperature at Point Conception where the whale southbound migration paths split, and timing of the ice melt and freeze during the previous feeding season. All combinations of melt and ice-over threshold values were tested in the GAMs. Some environmental variables only changed once per year in the GAMs and are listed as year-specific in Table 3. When these variables were tested, the year and yearspecific variable were not used in the same model to avoid correlation. For the same reason, the day vari-

Table 3. Predictor variables used in generalized additive models. All variables below the dashed line are environmental variables, and variables above the dashed line are used in the null hypothesis models

\begin{tabular}{|c|c|c|c|}
\hline Description & Method & Type & $\begin{array}{c}\text { Migration } \\
\text { seasons }\end{array}$ \\
\hline Start year of the migration season & Acoustic, Visual & Categorical & All \\
\hline Day (with 1 Dec = 1) & Acoustic, Visual & Continuous & All \\
\hline Hour of the day $(0-23)$ & Acoustic & Continuous, Cyclic & All \\
\hline Time of day (day or night) & Acoustic & Categorical & All \\
\hline Mean hourly probability of detection & Acoustic & Continuous & All \\
\hline Log of the proportion of day with effort & Visual & Offset & All \\
\hline Offshore temperature ${ }^{a}$ & Acoustic & Continuous (year-specific) & All \\
\hline Nearshore temperature ${ }^{a}$ & Visual & Continuous (year-specific) & All \\
\hline Point Conception temperature ${ }^{a, b}$ & Acoustic, Visual & Continuous (year-specific) & Not 2013-2014 \\
\hline Days since fall ice-over ${ }^{c}$ & Acoustic, Visual & Continuous & Not 2011-2012 \\
\hline Difference from mean ice-over date ${ }^{a}$ & Acoustic, Visual & Continuous (year-specific) & Not 2011-2012 \\
\hline Length of the ice-free season ${ }^{\mathrm{a}}$ & Acoustic, Visual & Continuous (year-specific) & Not 2011-2012, 2012-2013 \\
\hline
\end{tabular}


able was replaced with days since fall ice-over to test if the date of the fall freeze was a better predictor of the migration timing than calendar date. To test if day and ice-over date estimated the migration timing better than day and year, the annual difference from the mean ice-over date was included as a year-specific variable. Temperature was tested to see if local water temperature affected the gray whale migration route. Since Point Conception is north of the monitoring sites in the Southern California Bight, Point Conception water temperature was only used as a predictor in full migration and southbound-only models.

\section{RESULTS}

Acoustic recordings and sightings allowed for monitoring of the gray whale Eschrichtius robustus migration along both major routes through the

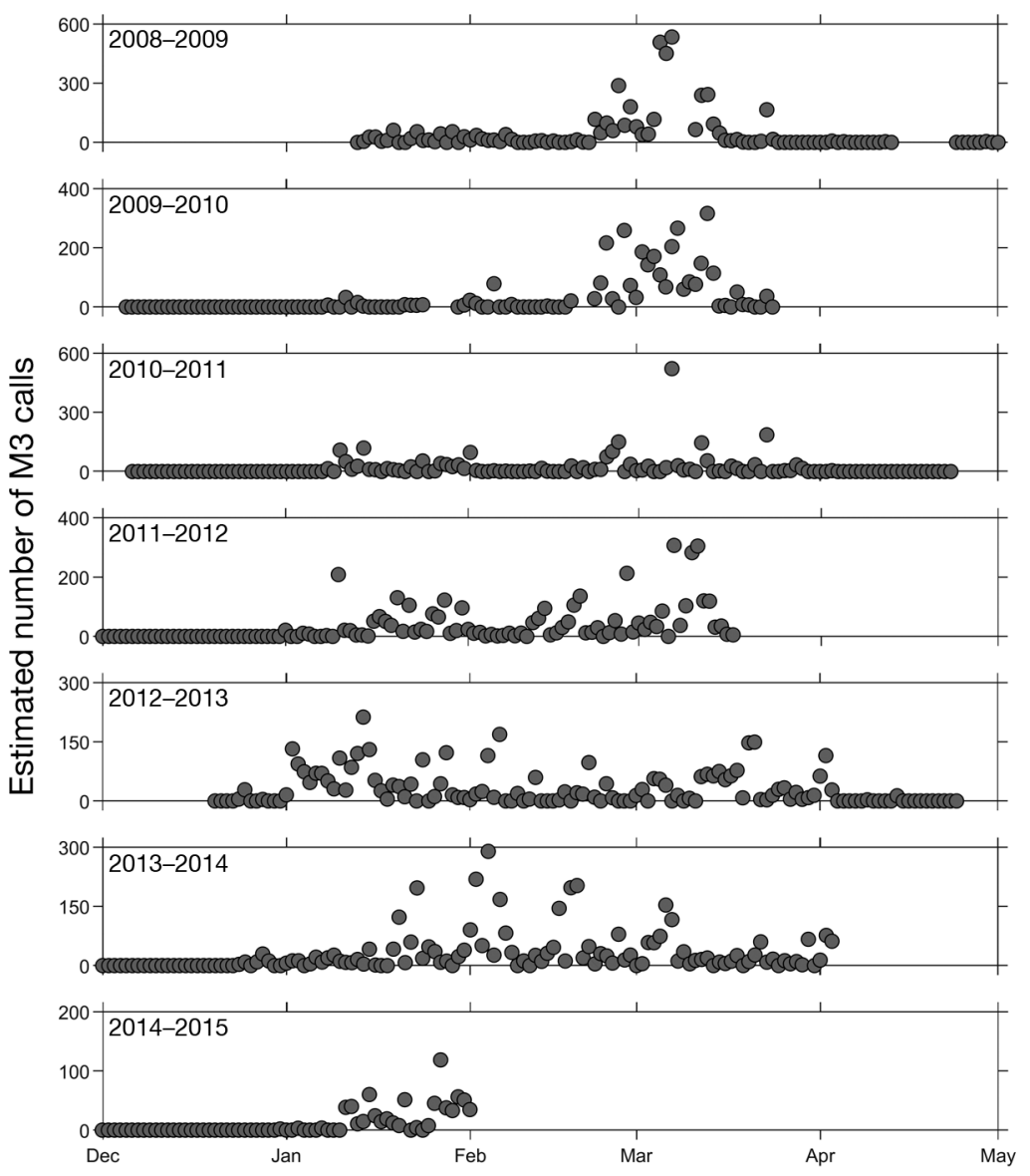

Fig. 3. Daily estimated number of gray whale M3 calls. Estimated calls are calculated using total detections, probability of detection, and effort (Eq. 2). Each point represents $1 \mathrm{~d}$. Days without points did not have effort. Note the differences in the $y$-axes for each migration season. Dates on $x$-axes extend from 1 December to 1 May
Southern California Bight for 7 consecutive migration seasons with very few gaps in coverage (Figs. 3-6). Two seasons of acoustic data (2008-2009 and 2009-2010) were missing a few days between HARP deployments and 3 seasons (2008-2009, 20092010, and 2011-2012) were missing days due to data recording errors, but these gaps were short compared to the total continuous recordings over $7 \mathrm{mi}$ gration seasons (Table 1). Other periods of no-effort were due to noise masking of calls, but all daily counts were corrected based on the proportion of the day with effort and probability of detection. Most of the gaps in the visual data were due to visual observers being unable to work at night or in rain, fog, or high wind, but total daily visual counts were corrected for proportion of the day with effort to get a minimum count of the number of gray whales.

Pulses of whales migrating during different phases of the migration were apparent in the visual time series. The southbound migration consisted of a steady stream of whales from December to February, but no clear peak (Fig. 5). In contrast, in most years, the northbound migration sightings peaked in March with northbound whales primarily without calves (Phase A) and then peaked again at the end of April or beginning of May with northbound presumably female whales with calves (Phase B) (Figs. 5 \& 6). No clear Phase A peak existed in ACS/LA sightings during 2009-2010 or 2010-2011, and no clear Phase B peak existed in ACS/LA 2008-2009, 2009-2010, 2010-2011, or GWC 2009-2010. Acoustic calls were recorded from December or January until the beginning of April, but very few or no calls were recorded after the start of April in years with effort (Figs. 3 \& 4). Three migration seasons, 20082009, 2009-2010, and 2011-2012, contained peaks in number and presence of calls at the beginning of March, but most years had more steady numbers or presence of calls over time with scattered days of high estimated total calls (Figs. $3 \& 4$ ). The number of hours with M3 calls (Fig. 4) can help us determine whether peaks in total calls (Fig. 3) are due to a few hours with high numbers of calls (perhaps due to a few whales with high calling 


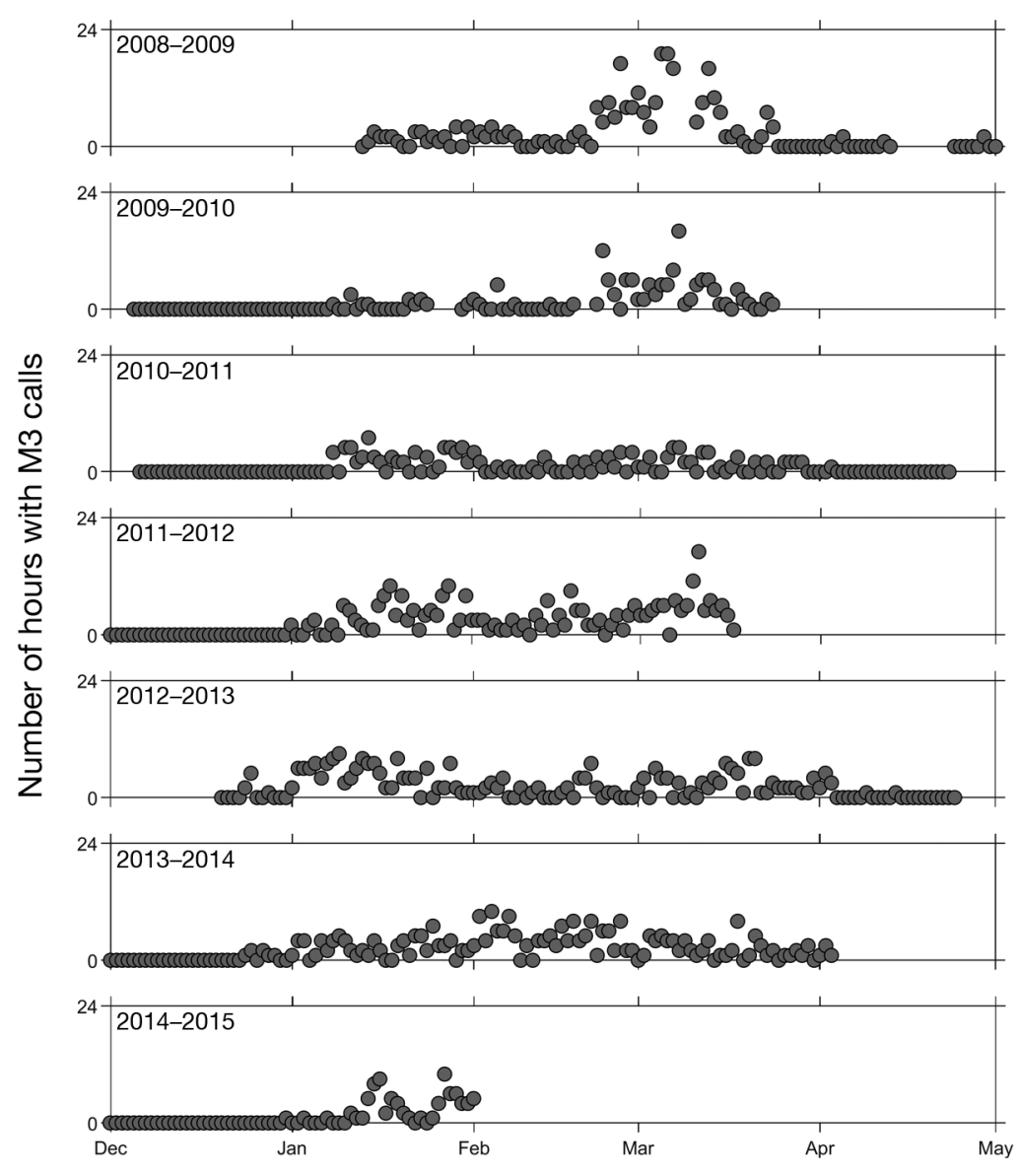

Fig. 4. Daily number of hours with gray whale M3 calls. Each point represents $1 \mathrm{~d}$. Days without points did not have effort. Dates on $\mathrm{X}$-axes extend from 1 December to 1 May

rates or a group of whales) or a full day of moderate calling rates (perhaps due to a steadier stream of whales and calls).

\subsection{Interannual comparison}

The eastern North Pacific gray whale population size increased with a growth rate of $5.20 \% \mathrm{yr}^{-1}(95 \%$ CI: -0.523 to $10.9 \%$ ) based on NOAA's reported population sizes for the 2009-2010, 2010-2011, 20142015, and 2015-2016 migration seasons (Durban et al. 2015, 2017) (Table 4, Fig. 7). This population growth rate was compared to the growth rate trends observed off southern California. Acoustic call counts and visual ACS/LA sightings were only included between the start and end days that were common to all the migration seasons. For acoustic recordings, Days 44-108 (13 January-18 March, 17 March in 2012 due to leap year) were included, and for ACS/LA sightings, Days 1-166 (1 December-15 May, 14 May on leap year) were included (counted starting with 1 December). Annual acoustic M3 call counts did not follow a clear trend, so a model was not fit to these data (Table 5). The number of estimated whales off of Los Angeles (ACS/LA census) increased the most over these years with a growth rate of $25.6 \% \mathrm{yr}^{-1}$ (95\% CI: $17.7-33.5 \%$ ). The growth rate was $31.1 \% \mathrm{yr}^{-1}$ for southbound whales only and $21.9 \% \mathrm{yr}^{-1}$ for northbound whales only. The annual northbound gray whales estimated from the GWC survey and model corrections increased by a growth rate of $10.7 \% \mathrm{yr}^{-1}$ (95\% CI: $6.06-15.4 \%)(8.80 \%$ for adults only). When comparing these growth rates to those of the population size growth rate, the ACS/LA sightings growth rate was statistically significantly greater than the population size growth rate $(p=0.0012$ for full migration, $p=6.9 \times$ $10^{-5}$ for southbound only, $\mathrm{p}=0.0063$ for northbound only). The growth rate for estimated northbound whales off Santa Barbara was also greater than the population size growth rate $(p=0.056$ for all whales, $p=0.092$ for adults only).

We estimated the number of whales that migrated through the $20 \mathrm{~km}$ radius search area surrounding the HARP between Days 44-108 (13 January18 March, 17 March in 2012) of each migration season using an estimated calling rate of 7.5 calls whale ${ }^{-1} \mathrm{~h}^{-1}$ and an estimated swim speed of $1.6 \mathrm{~m} \mathrm{~s}^{-1}$ (Guazzo et al. 2017, in press) (Table 5). This method assumes that gray whales call and swim at the same rate in the Southern California Bight as they do farther north at Granite Canyon, that calling rate is constant from year to year, and that the average calling rate over the full migration season is an appropriate estimate of the average calling rate over these $65 \mathrm{~d}$. The estimated number of whales migrating through the search area over these days was $<10 \%$ of the population in most years.

The gray whale feeding area was essentially icefree from the beginning of August until the beginning of November every year, but the timing of the start of the spring melt varied considerably (Fig. 8). The mean spring melt day was approximately 22 May for $90 \%$ sea ice concentration, 18 June for $50 \%$ sea ice concentration, and 22 July for $10 \%$ sea ice concentration. The earliest melt was 3 May (2008), and the latest was 12 June (2009) as measured by the 


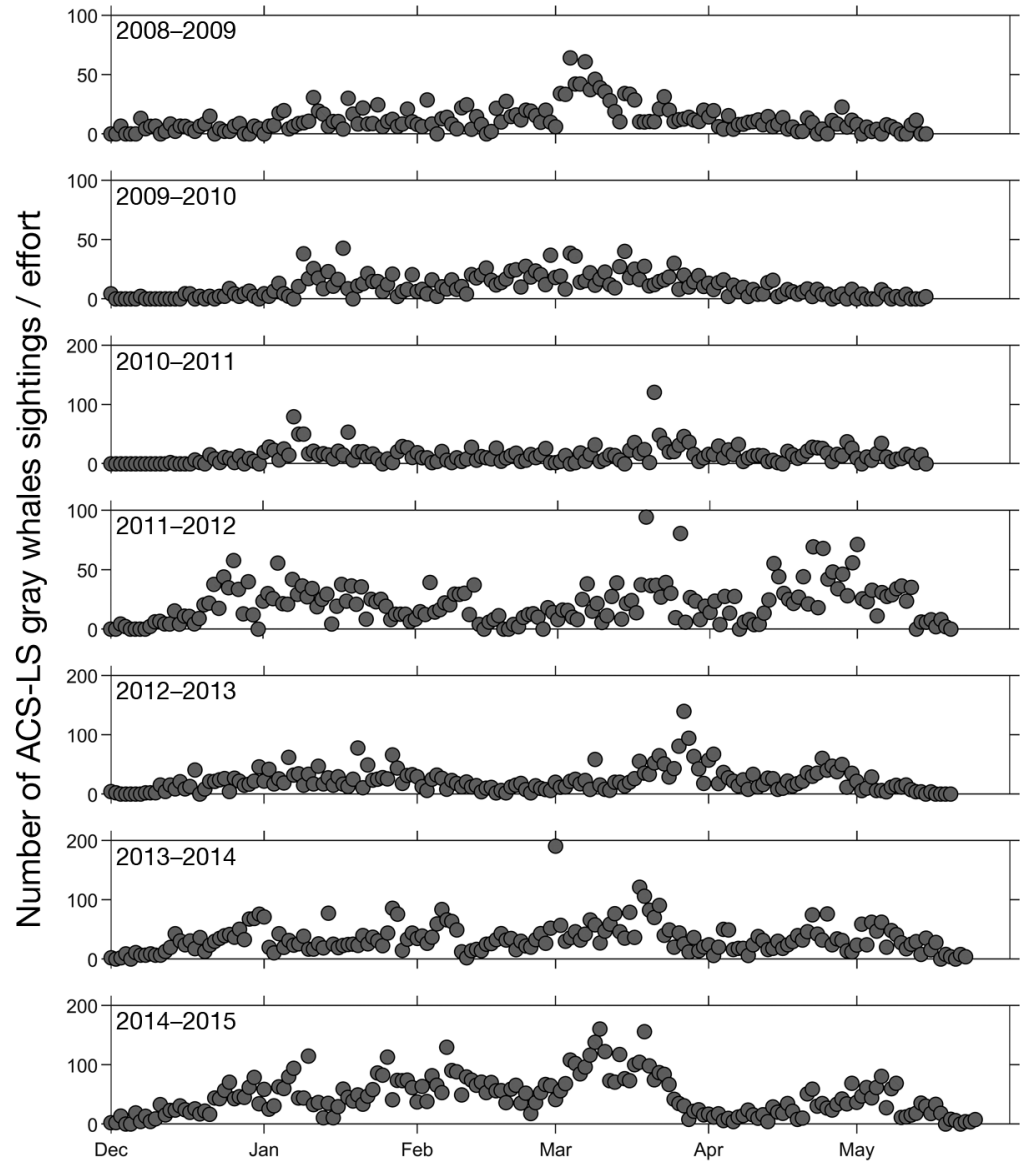

Fig. 5. Daily estimated number of gray whale sightings off Los Angeles from the American Cetacean Society - Los Angeles (ACS/LA) census. Values were calculated by dividing the daily counts by the proportion of the day with effort (Eq. 3). Each point represents 1 d. Days without points did not have effort. Note the differences in the $y$-axes for each migration season. Dates on $x$-axes extend from 1 December to 1 June

sured from last day in the spring with $90 \%$ sea ice concentration to the first day in the fall with $10 \%$ sea ice concentration).

The mean temperature of the upper $10 \mathrm{~m}$ of the water column across the winter CalCOFI cruises from these $7 \mathrm{yr}$ was $14.43^{\circ} \mathrm{C}$ at the nearshore site and $14.45^{\circ} \mathrm{C}$ at the offshore site (Table 6). Point Conception was usually slightly cooler and had a mean temperature of $13.82^{\circ} \mathrm{C}$. The nearshore and the offshore sites were always within $0.4^{\circ} \mathrm{C}$ of each other, with the nearshore site warmer than the offshore site in 2009, 2012, and 2015, and the offshore site warmer than the nearshore site in the other years. The standard deviation across all 3 sites was the least in 2009 and 2013, and these were the only 2 years when the temperature at Point Conception was greater than one of the more southerly sites. The standard deviation across all 3 sites was the greatest in 2011. The coldest year across all 3 sites was 2013, and the warmest year was 2015.

\subsection{Generalized additive model regression analysis}

In all comparisons, the null model without sea ice or temperature variables had an AIC equivalent to, or less than, the best model with environmen-

last time the average sea ice concentration dropped below $90 \%$. In most years, the amount of time between the $90 \%$ sea ice concentration 'melt day' and when the feeding area was ice-free was $<2$ mo, but in 2008 and 2010, the melt took $~ 3$ mo. The fall ice-over occurred much more rapidly and the gray whale feeding area was covered in ice within 1 mo after the freeze started. The mean ice-over day was approximately 1 November for $10 \%$ sea ice concentration, 11 November for $50 \%$ sea ice concentration, and 24 November for $90 \%$ sea ice concentration and was much more consistent between years than melt day. The earliest ice-over occurred on 28 October (2010) and the latest on 7 November (2009) (as measured by $10 \%$ sea ice concentration). The mean length of the ice-free season was $159.8 \mathrm{~d}$ with a minimum of $143 \mathrm{~d}$ in 2013 and a maximum of $178 \mathrm{~d}$ in 2010 (mea- tal variables, indicating that including environmental variables did not improve the fit of the generalized additive model. In addition, in the models with environmental variables, the predicted functions relating the environmental variables to presence or number of whales had no apparent trends. The best null models included all the temporal variables as well as the probability of detection (for acoustic call presence or absence) or proportion of the day with effort (for sightings) variables.

In every case, including calendar day in the model resulted in a significantly better model (lower AIC) than including number of days since ice-over (other variables included were year, hour, daytime, and probability of detection or effort). Including day with difference from the mean ice-over date instead of year did not improve the model, and in most cases, the 

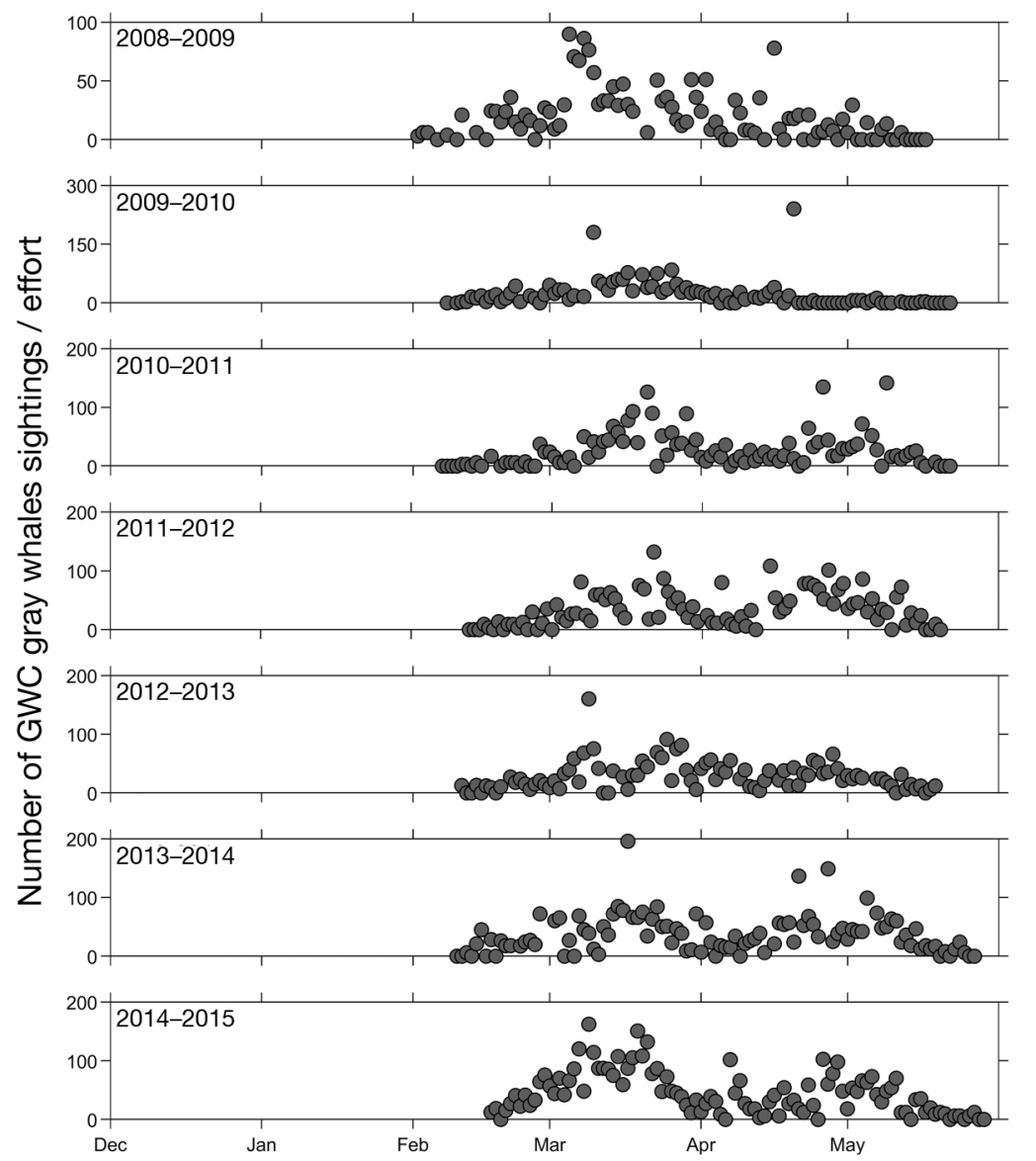

Fig. 6. Daily estimated number of northbound gray whale sightings off Santa Barbara from the Gray Whales Count (GWC) survey. Values were calculated by dividing the daily counts by the proportion of the day with effort (Eq. 3). Each point represents $1 \mathrm{~d}$. Days without points did not have effort. Note the differences in the $y$-axes for each migration season. Dates on $x$-axes extend from 1 December to 1 June

model with year, day, hour, daytime, and probability of detection or effort still had a significantly lower AIC value.

The best acoustic hourly call presence model included year, day, hour, time of day, and probability of detection (Fig. 9). Year did not show a clear trend with acoustic presence, and the pattern appears cyclical. Acoustic presence as a function of day is similar to what was observed in the acoustic time series. The function increased rapidly for the first month and then remained fairly constant with a small peak just before Day 100 (early March) and then decreased after that. Acoustic presence as a function of hour reached its maximum in the early morning hours before sunrise, and its minimum around sunset. In addition, acoustic presence was greater at night than during the day. Acoustic presence as a function of probability of detection had a decreasing positive slope as probability of detection increased, possibly because presence or absence was not as strongly affected by probability of detection as the total call count. Acoustic daily presence was also modeled to ensure that the timescale of observation was not causing relationships with environmental variables to be masked by the noise in hourly presence, but these results were similar to the hourly call presence results.

Both models based on visual data showed similar trends for number of sightings (Figs. 10 \& 11). Daily visual counts increased as a function of year as observed when comparing the number of sightings across years in Table 4. For the ACS/LA census, sightings increased rapidly during the first month, similar to the acoustic presence model, but the peak slightly after Day 100 (midMarch) was much more pronounced and there was a second peak around Day 150 (end of April). These 2 later peaks were also observed in the GWC survey northbound sightings model.

\section{DISCUSSION}

The gray whale Eschrichtius robustus Southern California Bight migration route choice contains a complicated trade-off. The coastal route may provide more protection from predators and opportunistic foraging but also has a greater risk of negative interactions with humans through entanglements, ship strikes, background noise, and pollution due to proximity to urban areas. Based on mapping of probable routes identified by Sumich \& Show (2011), offshore routes save about 20 to $25 \mathrm{~km}$ each way, but the deeper water and reduced cover from predators may deter some whales. In addition, whales traveling along the offshore route by San Clemente may be impacted by US Navy activities. By quantifying the number of calls produced near an offshore site and the number of whales passing coastal locations as functions of time, we can better understand the seasonal cycle of the gray whale migration through the Southern California Bight.

Although variability existed in the acoustic M3 call time series and the visual sightings time series, the 
Table 4. Interannual changes in population size and nearshore sightings. NOAA's population size estimates are published by Durban et al. $(2015,2017)$. The census did not occur in years with dashes. Even though we did not include visual or acoustic data from 2015-2016, the abundance estimates from NOAA's visual census were included for this year to increase the sample size and precision of the trend since the abundance estimate in 2014-2015 had wide probability intervals. American Cetacean Society - Los Angeles (ACS/LA) raw sightings between Days 1-166 (1 December-15 May, 14 May on leap year) were corrected for proportion of the day on-effort, but these sightings were not corrected for probability of detection and so values are relative for this site and should not be compared between sites. Raw counts off Santa Barbara (GWC) were corrected using a probability of detection model (Durban et al. 2015). All values are estimates. The growth rate is an exponential growth rate (Eq. 6)

\begin{tabular}{|lccc|}
\hline $\begin{array}{l}\text { Migration } \\
\text { season }\end{array}$ & $\begin{array}{c}\text { NOAA's } \\
\text { population size }\end{array}$ & $\begin{array}{c}\text { Los Angeles } \\
\text { full migration }\end{array}$ & $\begin{array}{c}\text { Santa Barbara } \\
\text { northbound model }\end{array}$ \\
\hline $2008-2009$ & - & 1991 & 2726 \\
$2009-2010$ & 21210 & 1687 & 2734 \\
$2010-2011$ & 20990 & 2338 & 3273 \\
$2011-2012$ & - & 3574 & 4171 \\
$2012-2013$ & - & 3841 & 3515 \\
$2013-2014$ & - & 5880 & 4628 \\
$2014-2015$ & 28790 & 7999 & 5094 \\
$2015-2016$ & 26960 & - & - \\
Growth rate & $5.20 \% \mathrm{yr}^{-1}$ & $25.6 \% \mathrm{yr}^{-1}$ & $10.7 \% \mathrm{yr}^{-1}$ \\
\hline
\end{tabular}

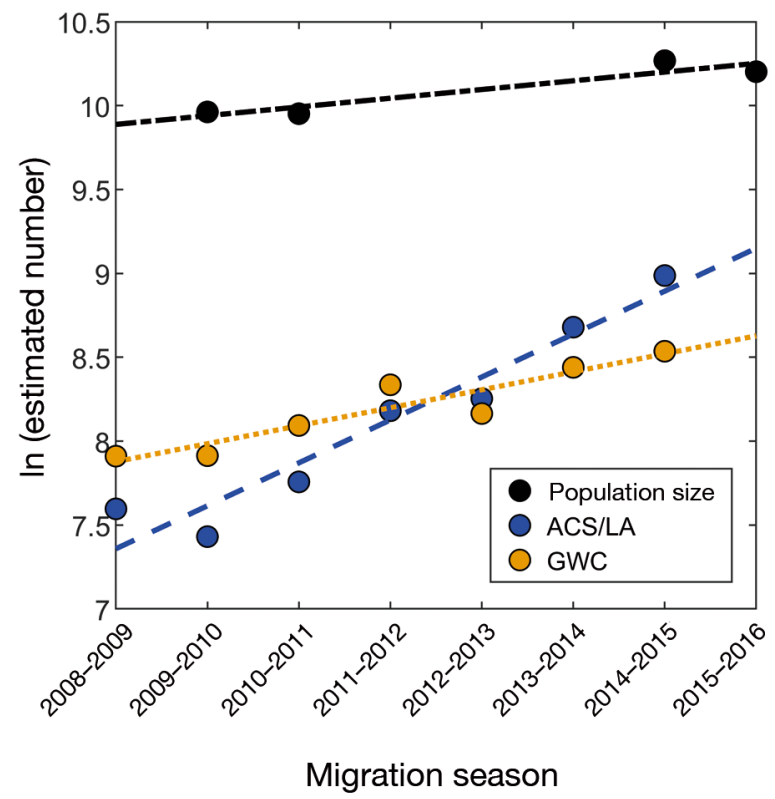

Fig. 7. Log-transformed interannual changes in population size and nearshore sightings. This plot shows the same data as Table 4, but with log-transformed estimated population size or nearshore sightings. The lines of best fit have a slope equal to the exponential growth rate $\left(5.20 \% \mathrm{yr}^{-1}\right.$ for NOAA's population size, $25.6 \% \mathrm{yr}^{-1}$ for sightings off Los Angeles (The American Cetacean Society - Los Angeles Chapter Gray Whale Census and Behavior Project [ACS/LA]), and $10.7 \% \mathrm{yr}^{-1}$ for sightings off Santa Barbara (Gray Whales Count [GWC]) annual migration timing and pattern through the Southern California Bight was consistent with observations from other locations along the eastern North Pacific gray whale migration route. The acoustic time series were more variable in timing and number of calls than the visual time series possibly because gray whales do not have to vocalize while migrating, and producing sound may make them more at risk for attacks from their primary predator, killer whales Orcinus orca (Linnaeus, 1758). Notably, acoustic calls along the offshore route started later in the season than visual sightings along the nearshore route, and offshore acoustic calls ended earlier in the season than nearshore visual sightings. This difference could be due to low calling rates and different behavior of different demographics of whales. As Guazzo et al. (in press) showed, gray whales migrating earlier in the southbound migration had the lowest calling rate of the southbound migrators. Even though all migrating gray whales traveled close to shore by Granite Canyon, very few calls were detected until the middle of December 2014, and no calls were recorded after the beginning of April 2015 (Guazzo et al. 2017). These times with low calls correspond to times when pregnant females migrate south and females with

Table 5. Estimated number of whales based on call counts for Days 44-108 (13 January-18 March, 17 March on leap year). These days were selected as this is the recording period that all years had in common. Acoustic M3 Calls have been corrected for probability of detection and proportion of the day with effort. Call counts for days during recording gaps were interpolated. Confidence intervals were calculated using the $95 \%$ non-simultaneous functional prediction interval of the power model fit to noise level versus probability of detection (Fig. 2). See Section 2 for equations

\begin{tabular}{|lccc|}
\hline $\begin{array}{l}\text { Migration } \\
\text { season }\end{array}$ & $\begin{array}{c}\text { Acoustic } \\
\text { M3 calls }\end{array}$ & $\begin{array}{c}\text { Confidence } \\
\text { interval }\end{array}$ & $\begin{array}{c}\text { Estimated } \\
\text { number } \\
\text { of whales }\end{array}$ \\
\hline $2008-2009$ & 4812 & $4564-5278$ & 3483 \\
$2009-2010$ & 3006 & $2838-3550$ & 2175 \\
$2010-2011$ & 1863 & $1761-2117$ & 1348 \\
$2011-2012$ & 3480 & $3271-3801$ & 2519 \\
$2012-2013$ & 2312 & $2185-2590$ & 1673 \\
$2013-2014$ & 3178 & $3003-3541$ & 2300 \\
\hline
\end{tabular}




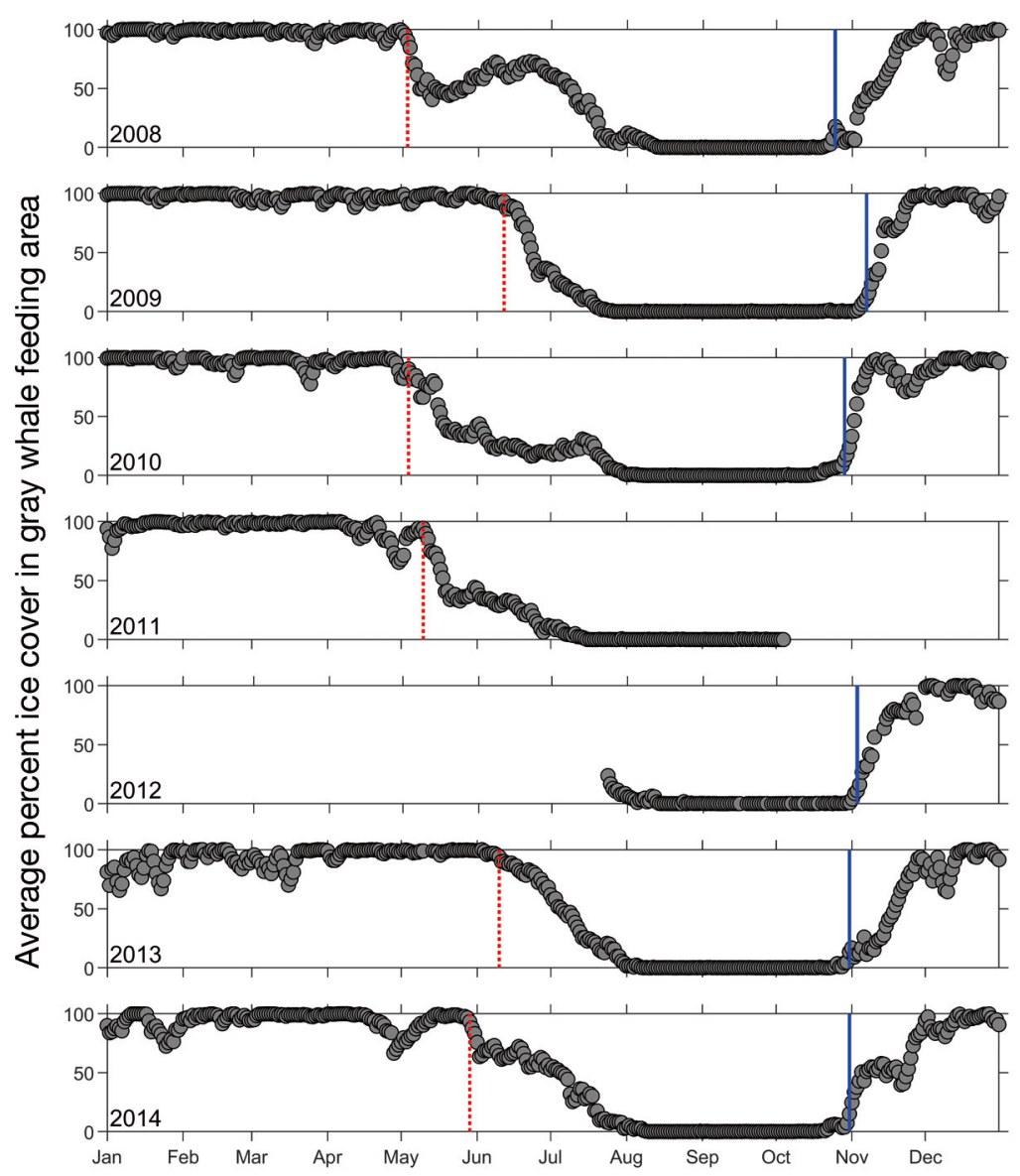

Fig. 8. Average sea ice concentration in the gray whale feeding area. The spring melt date was defined as the last date in the spring when the average sea ice concentration dropped below a threshold (here we are showing the $90 \%$ threshold as a red dotted line), and the fall ice-over date was defined as the first date in the fall when the average sea ice concentration increased above a threshold (here we are showing the $10 \%$ threshold as a blue solid line). To test for sensitivity of the GAM to different definitions of melt and ice-over, we tested thresholds of $10 \%, 50 \%$, and $90 \%$ average sea ice concentration to define the melt and ice-over dates. Sea ice concentration was measured on $6.25 \mathrm{~km}$ square grids

Table 6. CalCOFI temperature measurements during winter cruises in January/February 2009-2015. Measurements are an average across the 2 temperature sensors and across depth from 0-10 m. Temperature was not measured at Point Conception temperature in 2014. Standard deviation values are calculated across the 3 sites for years with measurements at all sites, and mean values are calculated across the available years for all sites

\begin{tabular}{|lcccc|}
\hline Year & Nearshore & Offshore & Point Conception & Standard deviation \\
\hline 2009 & $13.80^{\circ} \mathrm{C}$ & $13.55^{\circ} \mathrm{C}$ & $13.70^{\circ} \mathrm{C}$ & $0.10^{\circ} \mathrm{C}$ \\
2010 & $14.90^{\circ} \mathrm{C}$ & $14.96^{\circ} \mathrm{C}$ & $14.30^{\circ} \mathrm{C}$ & $0.29^{\circ} \mathrm{C}$ \\
2011 & $14.32^{\circ} \mathrm{C}$ & $14.62^{\circ} \mathrm{C}$ & $12.90^{\circ} \mathrm{C}$ & $0.75^{\circ} \mathrm{C}$ \\
2012 & $14.32^{\circ} \mathrm{C}$ & $14.11^{\circ} \mathrm{C}$ & $13.61^{\circ} \mathrm{C}$ & $0.30^{\circ} \mathrm{C}$ \\
2013 & $12.37^{\circ} \mathrm{C}$ & $12.76^{\circ} \mathrm{C}$ & $12.50^{\circ} \mathrm{C}$ & $0.16^{\circ} \mathrm{C}$ \\
2014 & $14.66^{\circ} \mathrm{C}$ & $14.86^{\circ} \mathrm{C}$ & - & - \\
2015 & $16.65^{\circ} \mathrm{C}$ & $16.34^{\circ} \mathrm{C}$ & $15.89^{\circ} \mathrm{C}$ & $0.32^{\circ} \mathrm{C}$ \\
Mean & $14.43^{\circ} \mathrm{C}$ & $14.45^{\circ} \mathrm{C}$ & $13.82^{\circ} \mathrm{C}$ & \\
\hline
\end{tabular}

calves migrate north (Rice \& Wolman 1971, Poole 1984). Acoustic detection may not be the best way of assessing presence of this demographic segment of the gray whale population. In addition, the GAM model showed a greater proportion of nighttime hours with calls compared to daytime hours. This diel change in calling behavior is consistent with observations at Granite Canyon where over twice as many calls were recorded at night compared to the day (Guazzo et al. 2017). Using a hydrophone array to localize calls similar to that utilized at Granite Canyon (Guazzo et al. 2017) would have reduced the uncertainty in number of calls since the search area could have been constrained to the region of the highest probability of detection.

Sumich \& Show (2011) reported high interannual variability in the number of whales taking an offshore route. We also found high interannual variability in the number of calls recorded, which could indicate interannual changes in the number of whales taking an offshore route near the hydrophone and/or changes in the calling rate of gray whales. No trend was observed in the number of calls recorded on the offshore hydrophone. We may expect an increasing trend along the offshore route due to an increasing gray whale population or a decreasing trend as more whales used the coastal route through the Southern California Bight. It is possible that these 2 trends counter-act each other so that the offshore route has experienced no net change in number of gray whales. Alternatively, the interannual variability in calling rate and slight changes in the offshore migration route may have resulted in no apparent trend in the acoustic data.

Over the 7 migration seasons between 2008-2009 and 2014-2015, an increasing proportion of gray whales used the nearshore route, as indicated by a greater growth rate of estimated 
whales off of Los Angeles and Santa Barbara than the population size growth rate. The growth rate at the ACS/LA census site was $\sim 5$-fold the population growth rate, and the growth rate at the GWC site was $\sim 2$-fold
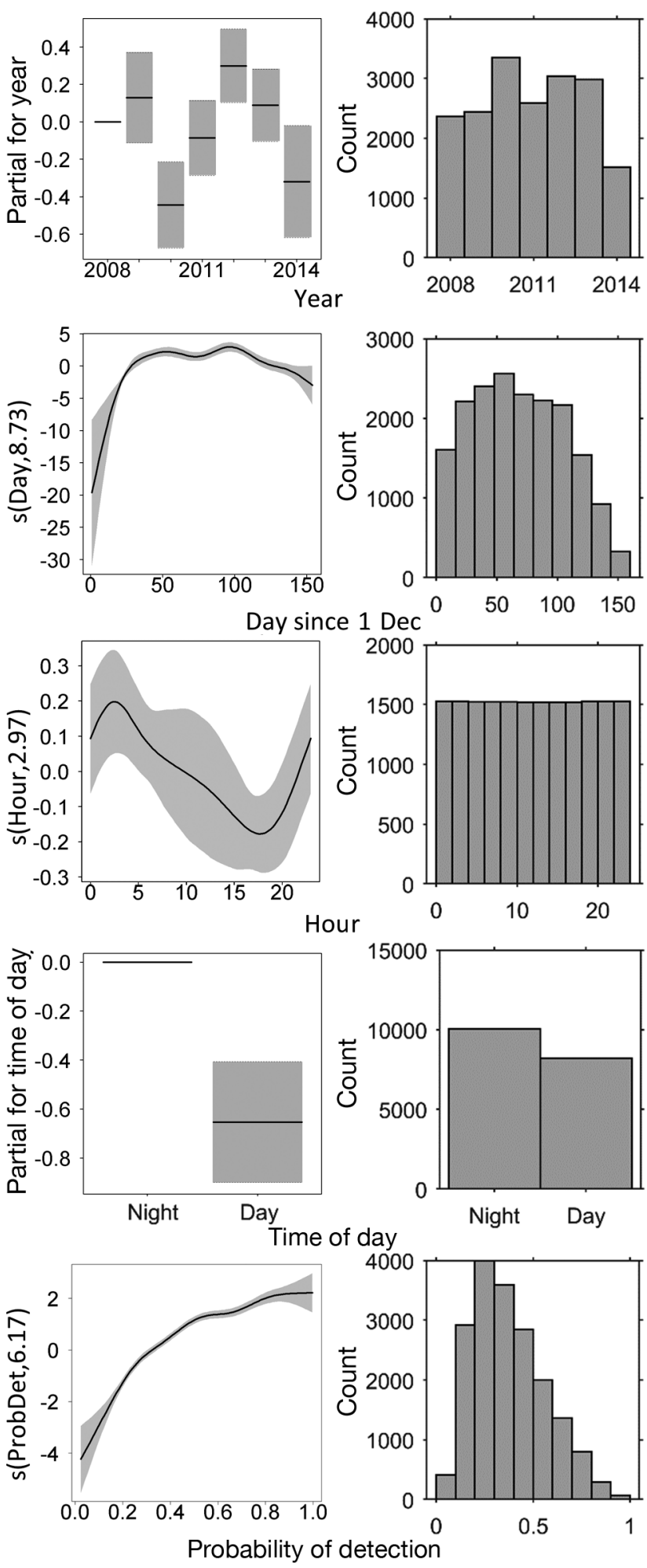

the population size growth rate. An increase in sightings due to increased probability of detection seems unlikely given that the same experienced observers anchored each shift, effort did not change across these years, and local whale watching boats anecdotally reported a similar increase in sightings. In addition, at the ACS/LA census location, fewer days had compromised visibility due to fog between 2008-2009 and 2010-2011 than between 2011-2012 and 2014-2015, indicating that the increase in sightings was not due to an increase in visibility. One possible explanation for these nearshore observations is that an increasing proportion of gray whales migrated past Los Angeles that may have bypassed it in the past in a more offshore route, but still intercepted the coast before Santa Barbara on their journey north. Another explanation for the increase in sightings along the coast could be explained by an increasing population size and the tendency for younger whales to prefer a coastal route (Sumich \& Show 2011). Mathematical support of this hypothesis is provided in the Appendix.

Assuming that offshore gray whale calling rate was constant between years and equal to the calling rate estimated farther north at Granite Canyon, in most years, $<10 \%$ of the population migrated through the area within $20 \mathrm{~km}$ of the hydrophone during Days $44-108$ when an average of $45 \%$ of ACS/LA census sightings were during these days (range: $30-63 \%$ ). This $10 \%$ value is lower than expected based on the estimate by Carretta et al. (2000) that an average of $>400$ whales were migrating through the offshore area every day between January and April 1999, which corresponds to almost the entire population migrating offshore through the Southern California Bight. Precise migration routes through the Southern California Bight are unknown, and a low number of whales may swim through the hydrophone search area because gray whales may be more dispersed or they may follow a different route, perhaps swimming along bathymetric ridges. Alternatively, gray whales may call at a lower rate in the

Fig. 9. Generalized additive model results for acoustic data. Hourly presence of gray whale M3 calls modeled as a function of year, day, hour, time of day, and probability of detection (left) and histograms of these variables (right). Day, hour, and probability of detection were fit with a spline fit and $8.73,2.97$, and 6.17 estimated degrees of freedom, respectively. Year and time of day were modeled as factors with 6 and 1 degrees of freedom, respectively. Shading indicates 2 standard error bounds. The histograms show the distribution of the number of hours of available data as a function of each variable 

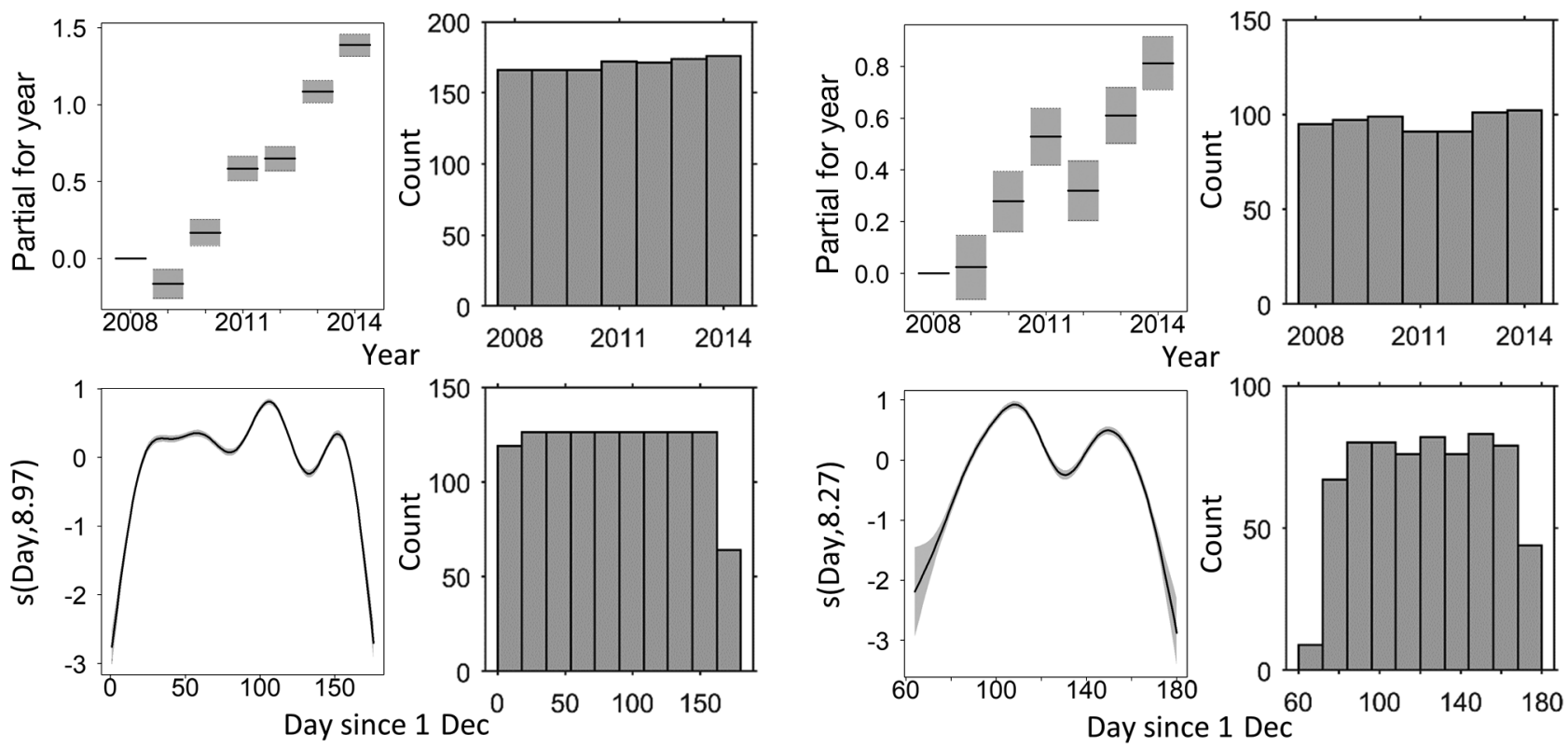

Fig. 10. Generalized additive model results for visual ACS/ LA census data. Daily counts of sighted gray whales by The American Cetacean Society - Los Angeles Chapter Gray Whale Census and Behavior Project (ACS/LA) modeled as a function of year and day (left) and histograms of these variables (right). Day was fit with a spline fit with 8.97 estimated degrees of freedom. Year was modeled as a factor with 6 degrees of freedom. Shading indicates 2 standard error bounds. The histograms show the distribution of the number of days of available data as a function of each variable. Proportion of the day with effort was included as an offset in this model

Southern California Bight. Gray whales often flee to shallow water when they are attacked by killer whales (e.g. Baldridge 1972), so it is possible that gray whales are more vulnerable in the deeper water offshore and call less often to avoid attracting predators, even though killer whales are less common in the Southern California Bight than farther north in Monterey Bay. Additionally, offshore waters are likely clearer than nearshore waters, and increased visibility may decrease the need for acoustic communication. These hypotheses could be tested by deploying a series of hydrophones along a line perpendicular to the coast, spaced at intervals that allow for all migrating gray whales to be within the search area of one hydrophone. This method would allow us to compare the number of calls as a function of distance from shore and calculate the calling rate through the Southern California Bight.

Several climatic events occurred between 2008 and 2015, but most notable was the warm 'Blob' of high ocean temperatures that was first detected at the end of 2013 and led into a strong El Niño in 2015-2016 (Bond et al. 2015, Jacox et al. 2016, Hu et al. 2017).

Fig. 11. Generalized additive model results for visual GWC survey data. Daily counts of sighted northbound gray whales by the Gray Whales Count (GWC) survey modeled as a function of year and day (left) and histograms of these variables (right). Day was fit with a spline fit with 8.27 estimated degrees of freedom. Year was modeled as a factor with 6 degrees of freedom. Shading indicates 2 standard error bounds. The histograms show the distribution of the number of days of available data as a function of each variable. Proportion of the day with effort was included as an offset in this model

Other ENSO events occurred in 2009-2010 (moderate El Niño), 2010-2011 (strong La Niña), and 20112012 (moderate La Niña) (Boening et al. 2012). The temperature difference across the 3 CalCOFI sites was the greatest in 2011 during the strong La Niña. The temperature of the upper $10 \mathrm{~m}$ at Point Conception was $\sim 1.6^{\circ} \mathrm{C}$ less than the mean temperature of the nearshore and offshore sites. However, the temperature difference from year to year was always greater than the variability between sites in a given year. The temperature was warmest across the 3 sites in 2015, during the Blob and the strong El Niño. Unfortunately, ice data were only available for part of the years in 2011 and 2012 during the strong La Niña, and the time series does not last long enough to see any effects on sea ice by the Blob and the strong El Niño.

The results of the GAM analysis suggest that over these years the gray whale migration may be cued more by intrinsic than the extrinsic factors included in this study. The best models (based on AIC values) of both gray whale acoustic presence and visual sightings included timing and effort or probability of detection predictor variables. Sea ice timing did not 
improve the models of gray whale sightings or calls. Possibly the need to give birth and mate drives the migration more than the surrounding environmental conditions. In addition, local temperature measurements did not improve the GAMs. Ocean temperature does not seem to affect which migration route the gray whales choose and this choice may be affected more by instinct or demographic factors. Further modeling should be done using acoustic and visual data from more years to assess if there are external factors that do sometimes affect the migration. Perhaps the gray whales are cued by certain changes in the environment on longer timescales. A major factor in the observed migration timing seems to be how far the whales have had to swim from their feeding areas. Since the 1980s, the primary gray whale feeding area has moved farther north (Moore et al. 2003, Coyle et al. 2007), and the timing of the migration has shifted later (Rugh et al. 2001). Over longer time periods, reductions in sea ice may result in the feeding area moving again, the migration route expanding, and the timing of the migration through California shifting even later.

\section{CONCLUSIONS}

By combining multiple methods of observation over several locations, we were able to better understand the gray whale Eschrichtius robustus migration in the Southern California Bight over 7 migration seasons. If the gray whale calling rate is the same as it is farther north off the central California coast, the proportion of the population that travels offshore through the $20 \mathrm{~km}$ hydrophone detection range is small and, although highly variable from year to year, shows no general trend. Analysis of acoustic data from a series of widely-spaced hydrophones deployed along a line perpendicular to the coast of the Southern California Bight would help to determine if the relatively low number of calls is due to a lower calling rate or to gray whales migrating through different parts of the Southern California Bight. Understanding migration routes through Southern California is necessary to define the anthropogenic impact on this population. Over these 7 migration seasons, the proportion of the population migrating along a nearshore route within sighting range of visual observers increased substantially, with the proportion migrating off Los Angeles increasing the most. High densities of shipping around the San Pedro Bay port complex and millions of people living and working in the metropolitan area around Los Angeles, in addi- tion to an increasing proportion of gray whales migrating along the coast, may result in increased negative impacts from ship strikes, fishing gear entanglements, background noise, and chemical pollution. Perhaps an increasing proportion of gray whales are using the nearshore route due to an increased population with a larger proportion of younger whales that may favor more nearshore routes compared to older whales that may migrate more offshore (Sumich \& Show 2011).

This analysis is a retrospective study of available data. Future work assessing how the migration patterns of gray whales may be affected by climate change should employ a designed study to reduce the number of variables. Ideally, this study should take place at a location like Granite Canyon where the entire population migrates within a defined area in order to reduce confounding variables related to unknown calling rates and distribution of whales. Acoustic data should be collected for 10 to 15 migration seasons to capture several climatic events and changes in prey abundance that may affect the migration. In years with population size estimates, these values could be used to compare calling rate between years. Finally, other variables that may impact gray whales should be measured. For example, benthic prey abundance should be quantified in the gray whale feeding area in the Arctic at the same sampling locations for the duration of the study. Benthic amphipod abundance has been measured as a function of location in the Arctic feeding areas (Brower et al. 2017) but has not been measured as a function of time on less than decadal time scales. Prey abundance and distribution is likely an important variable that would affect the gray whale population size, health, and migration timing.

Generalized additive models of both acoustic and visual data led to the conclusion that the gray whale migration may be cued and influenced more by the whales' biological clock and instincts than by the environmental parameters included in this study. Modeling over longer duration time series and with more environmental variables will help to assess and predict how the gray whale migration will be affected by future, longer timescale environmental changes. Generalized additive modeling of acoustic data is a useful tool to determine the influence of several variables on the detection and presence of marine mammals in areas that are difficult to monitor visually.

Acknowledgments. Acoustic data collection was supported by grants from the US Army Corps of Engineers using funds provided by the US Navy's Pacific Fleet through the Cooper- 
ative Ecosystem Studies Units. The authors would specifically like to thank Chip Johnson from Pacific Fleet. R.A.G. was awarded the Science, Mathematics \& Research for Transformation (SMART) Scholarship, funded by the Under Secretary of Defense/Research \& Engineering National Defense Education Program / BA-1, Basic Research. A.S.J. thanks the scores of dedicated citizen scientists, trained volunteers who have helped collect and record data for the ACS/LA Gray Whale Census and Behavior Project, as well as the Point Vicente Interpretive Center staff who have gone out of their way to provide a terrific observation platform. Collaborators for the ACS/LA census include Dave Rugh, Kim Sheldon, and Wayne Perryman (NOAA AFSC and SWFSC) and Dave Janiger (NHMLAC). M.H.S. thanks the Counters, a team of diverse, passionate individuals who make GWC possible. GWC collaborators include Dave Weller, John Durban, and Wayne Perryman (NOAA SWFSC), John Calambokidis (Cascadia Research Collective), Sean Wiggins (Scripps Whale Acoustics Lab), and Cris Sandoval (Coal Oil Point Reserve). GWC is supported by generous and committed foundations and organizations, including an anonymous foundation administered by the Orange County Community Foundation and the Pacific Life Foundation. We are grateful for Wayne Perryman and Trevor Joyce for sharing what they have learned about the effects of sea ice on gray whale calf production. We thank Josh Jones for retrieving the sea ice data and Mati Kahru for help with the WIM/WAM software used to process the sea ice data. Sarah Creel, Tyler Helble, Mark Ohman, and Dave Weller provided feedback that improved this study.

\section{LITERATURE CITED}

Baldridge A (1972) Killer whales attack and eat a gray whale. J Mammal 53:898-900

Bay S, Jones BH, Schiff K (1999) Study of the impact of stormwater discharge on Santa Monica Bay. Technical Report USCSG-TR-02-99, University of Southern California, Sea Grant Program, Los Angeles, CA

Boening C, Willis JK, Landerer FW, Nerem RS, Fasullo J (2012) The 2011 La Niña: so strong, the oceans fell. Geophys Res Lett 39:L19602

Bond NA, Cronin MF, Freeland H, Mantua N (2015) Causes and impacts of the 2014 warm anomaly in the NE Pacific. Geophys Res Lett 42:3414-3420

* Bradford AL, Weller DW, Ivashchenko YV, Burdin AM, Brownell RL Jr (2009) Anthropogenic scarring of western gray whales (Eschrichtius robustus). Mar Mamm Sci 25: 161-175

Brower AA, Ferguson MC, Schonberg SV, Jewett SC, Clarke JT (2017) Gray whale distribution relative to benthic invertebrate biomass and abundance: Northeastern Chukchi Sea 2009-2012. Deep Sea Res II 144:156-174

* Buckland ST, Breiwick JM, Cattanach KL, Laake JL (1993) Estimated population size of the California gray whale. Mar Mamm Sci 9:235-249

Carretta JV, Lowry MS, Stinchcomb CE, Lynn MS, Cosgrove RE (2000) Distribution and abundance of marine mammals at San Clemente Island and surrounding offshore waters: results from aerial and ground surveys in 1998 and 1999. Technical report, National Oceanic and Atmospheric Administration, US National Marine Fisheries Service, Southwest Fisheries Science Center, La Jolla, CA
Collins MD (1993) A split-step Padé solution for the parabolic equation method. J Acoust Soc Am 93:1736-1742

Comiso JC (2012) Large decadal decline of the Arctic multiyear ice cover. J Clim 25:1176-1193

Coyle KO, Bluhm B, Konar B, Blanchard A, Highsmith RC (2007) Amphipod prey of gray whales in the northern Bering Sea: comparison of biomass and distribution between the 1980s and 2002-2003. Deep Sea Res II 54: 2906-2918

* Crane NL, Lashkari K (1996) Sound production of gray whales, Eschrichtius robustus, along their migration route: a new approach to signal analysis. J Acoust Soc Am 100:1878-1886

Cummings WC, Thompson PO (1971) Gray whales, Eschrichtius robustus, avoid the underwater sounds of killer whales, Orcinus orca. Fish Bull 69:525-530

Durban JW, Weller DW, Lang AR, Perryman WL (2015) Estimating gray whale abundance from shore-based counts using a multilevel Bayesian model. J Cetacean Res Manag 15:61-68

Durban JW, Weller DW, Perryman WL (2017) Gray whale abundance estimates from shore-based counts off California in 2014/15 and 2015/16. Paper SC/A17/GW/06 presented to the International Whaling Commission Scientific Committee. https://archive.iwc.int/?r=6437\&k $=7 \mathrm{f} 10 \mathrm{ebac} 2 \mathrm{C}$

*Fritsch FN, Carlson RE (1980) Monotone piecewise cubic interpolation. SIAM J Numer Anal 17:238-246

* Gardner S, Chávez-Rosales S (2000) Changes in the relative abundance and distribution of gray whales (Eschrichtius robustus) in Magdalena Bay, Mexico during an El Niño event. Mar Mamm Sci 16:728-738

Guazzo RA, Helble TA, D'Spain GL, Weller DW, Wiggins SM, Hildebrand JA (2017) Migratory behavior of eastern North Pacific gray whales tracked using a hydrophone array. PLOS ONE 12:e0185585

Guazzo RA, Weller DW, Europe HM, Durban JW, D'Spain GL, Hildebrand JA (in press) Migrating eastern North Pacific gray whale call and blow rates estimated from acoustic recordings, infrared camera video, and visual sightings. Sci Rep doi:10.1038/s41598019-49115-y

Gulland FMD, Pérez-Cortés MH, Urbán RJ, Rojas-Bracho L and others (2005) Eastern North Pacific gray whale (Eschrichtius robustus) unusual mortality event, 19992000. NOAA Tech Memo NMFS-AFSC-150, US Department of Commerce, Seattle, WA

Hastie TJ, Tibshirani RJ (1990) Generalized additive models. Monographs on Statistics and Applied Probability, Vol 43. Chapman \& Hall, London

*Heaney KD, Campbell RL (2016) Three-dimensional parabolic equation modeling of mesoscale eddy deflection. J Acoust Soc Am 139:918-926

*Heaney KD, Prior M, Campbell RL (2017) Bathymetric diffraction of basin-scale hydroacoustic signals. J Acoust Soc Am 141:878-885

*Helble TA, Ierley GR, D'Spain GL, Roch MA, Hildebrand JA (2012) A generalized power-law detection algorithm for humpback whale vocalizations. J Acoust Soc Am 131: 2682-2699

*Helble TA, D'Spain GL, Hildebrand JA, Campbell GS, Campbell RL, Heaney KD (2013) Site specific probability of passive acoustic detection of humpback whale calls from single fixed hydrophones. J Acoust Soc Am 134: 2556-2570 
Highsmith RC, Coyle KO (1991) Amphipod life histories: community structure, impact of temperature on decoupled growth and maturation rates, productivity, and $\mathrm{P}: \mathrm{B}$ ratios. Am Zool 31:861-873

Hu ZZ, Kumar A, Jha B, Zhu J, Huang B (2017) Persistence and predictions of the remarkable warm anomaly in the Northeastern Pacific Ocean during 2014-16. J Clim 30: 689-702

Jacox MG, Hazen EL, Zaba KD, Rudnick DL, Edwards CA, Moore AM, Bograd SJ (2016) Impacts of the 2015-2016 El Niño on the California Current System: early assessment and comparison to past events. Geophys Res Lett 43:7072-7080

Kahru M (2001) Windows image manager: image display and analysis program for Microsoft Windows with special features for satellite images. www.wimsoft.com

Kawanishi T, Sezai T, Ito Y, Imaoka K and others (2003) The advanced microwave scanning radiometer for the earth observing system (AMSR-E), NASDA's contribution to the EOS for global energy and water cycle studies. IEEE Trans Geosci Remote Sens 41:184-194

Liu J, Curry JA, Hu Y (2004) Recent Arctic sea ice variability: connections to the Arctic Oscillation and the ENSO. Geophys Res Lett 31:L09211

Malme C, Miles P, Clark C, Tyack P, Bird J (1984) Investigations of the potential effects of underwater noise from petroleum-industry activities on migrating gray-whale behavior. Phase 2: January 1984 migration. Tech Rep PB86-218377/XAB; BBN-5586, Bolt, Beranek and Newman, Cambridge, MA

Mantua NJ, Hare SR (2002) The Pacific Decadal Oscillation. J Oceanogr 58:35-44

McDonald MA, Hildebrand JA, Wiggins SM (2006) Increases in deep ocean ambient noise in the Northeast Pacific west of San Nicolas Island, California. J Acoust Soc Am 120:711-718

* McDonald MA, Hildebrand JA, Wiggins SM, Ross D (2008) A 50 year comparison of ambient ocean noise near San Clemente Island: a bathymetrically complex coastal region off southern California. J Acoust Soc Am 124:1985-1992

*Moore SE, Grebmeier JM, Davies JR (2003) Gray whale distribution relative to forage habitat in the northern Bering Sea: current conditions and retrospective summary. Can J Zool 81:734-742

Moore SE, Wynne KM, Kinney JC, Grebmeier JM (2007) Gray whale occurrence and forage southeast of Kodiak, Island, Alaska. Mar Mamm Sci 23:419-428

Noad MJ, Dunlop RA, Mack AK (2017) Changes in humpback whale singing behavior with abundance: implications for the development of acoustic surveys of cetaceans. J Acoust Soc Am 142:1611-1618

* Overland JE, Stabeno PJ (2004) Is the climate of the Bering Sea warming and affecting the ecosystem? Eos (Wash DC) 85:309-312

Parks SE, Johnson M, Nowacek D, Tyack PL (2010) Individual right whales call louder in increased environmental noise. Biol Lett 7:33-35

Perryman WL, Donahue MA, Perkins PC, Reilly SB (2002) Gray whale calf production 1994-2000: Are observed fluctuations related to changes in seasonal ice cover? Mar Mamm Sci 18:121-144

Perryman WL, Reilly SB, Rowlett RA (2014) Results of surveys of northbound gray whale calves 2001-2010 and examination of the full seventeen year series of estimates from the Piedras Blancas Light Station. Paper SC/M11/
AWMP3 presented to the International Whaling Commission Scientific Committee. https://iwc.int/document_444 \% Piepenburg D (2005) Recent research on Arctic benthos: common notions need to be revised. Polar Biol 28:733-755

Poole MM (1984) Migration corridors of gray whales along the central California coast, 1980-1982. In: Jones ML, Swartz SL, Leatherwood S (eds) The gray whale: Eschrichtius robustus, Chapter 16. Academic Press, Orlando, FL, p 389-407

Rice DW, Wolman AA (1971) The life history and ecology of the gray whale (Eschrichtius robustus). The American Society of Mammalogists, Seattle, WA

* Rolland RM, Parks SE, Hunt KE, Castellote M and others (2012) Evidence that ship noise increases stress in right whales. Proc Biol Sci 279:2363-2368

Rugh DJ, Shelden KEW, Schulman-Janiger A (2001) Timing of the gray whale southbound migration. J Cetacean Res Manag 3:31-40

Salvadeo CJ, Gómez-Gallardo UA, Nájera-Caballero M, Urbán-Ramírez J, Lluch-Belda D (2015) The effect of climate variability on gray whales (Eschrichtius robustus) within their wintering areas. PLOS ONE 10:e0134655

Schonberg SV, Clarke JT, Dunton KH (2014) Distribution, abundance, biomass and diversity of benthic infauna in the Northeast Chukchi Sea, Alaska: relation to environmental variables and marine mammals. Deep Sea Res II 102:144-163

Serreze MC, Barrett AP, Stroeve JC, Kindig DN, Holland MM (2009) The emergence of surface-based Arctic amplification. Cryosphere 3:11-19

Shelden KEW, Rugh DJ, Schulman-Janiger A (2004) Gray whales born north of Mexico: indicator of recovery or consequence of regime shift? Ecol Appl 14:1789-1805

Spreen G, Kaleschke L, Heygster G (2008) Sea ice remote sensing using AMSR-E 89-GHz channels. J Geophys Res 113:C02S03

Sumich JL (2014) E. robustus: the biology and human history of gray whales. Whale Cove Marine Education, Corvallis, OR

Sumich JL, Show IT (2011) Offshore migratory corridors and aerial photogrammetric body length comparisons of southbound gray whales, Eschrichtius robustus, in the Southern California Bight, 1988-1990. Mar Fish Rev 73:28-34

Urbán-Ramírez J, Gómez-Gallardo UA, Ludwig S (2003) Abundance and mortality of gray whales at Laguna San Ignacio, Mexico, during the 1997-98 El Niño and the 1998-99 La Niña. Geofis Int 42:439-446

Weller DW, Ivashchenko YV, Tsidulko GA, Burdin AM, Brownell RL Jr (2002) Influence of seismic surveys on western gray whales off Sakhalin Island, Russia in 2001. Paper SC/54/BRG14 presented to the International Whaling Commission Scientific Committee. https://digitalcommons.unl.edu/usdeptcommercepub/73/

Whittaker JM, Goncharov A, Williams SE, Müller RD, Leitchenkov G (2013) Global sediment thickness data set updated for the Australian-Antarctic Southern Ocean. Geochem Geophys Geosyst 14:3297-3305

Wiggins SM, Hildebrand JA (2007) High-frequency Acoustic Recording Package (HARP) for broad-band, longterm marine mammal monitoring. In: 2007 Symposium on Underwater Technology and Workshop on Scientific Use of Submarine Cables and Related Technologies Tokio, 17-20 April 2007. IEEE, p 551-557

Wood SN (2006) Generalized additive models: an introduction with R. CRC Press, Boca Raton, FL 


\section{Appendix.}

The greater growth rate of gray whale sightings along the southern California coast compared to the growth rate of the eastern North Pacific gray whale population may be due to a small, but increasing, proportion of the population using the coastal route. Solving for the growth rate, $r$, in the exponential growth equation (Eq. 6) results in:

$$
r=\frac{1}{t} \ln \frac{N}{N_{0}}
$$

where $t$ is time in year, $N$ is the annual counts, and $N_{0}$ is the count for the start of the time series. According to Table 4 , the growth rate of the population $\left(r_{\text {pop }}\right)$ was $5.20 \% \mathrm{yr}^{-1}$. Let $M_{0}$ and $N_{0}$ equal the number of gray whales migrating past Los Angeles and the number in the full population, respectively, at the start of this time series. If, for example, the entire increase in the number of whales in the population over these years $\left(N-N_{0}\right)$ was equal to the increase in number migrating past Los Angeles, estimated by the American Cetacean Society - Los Angeles Chapter Gray Whale Census and Behavior Project, then the number migrating past Los Angeles would be:

$$
M=M_{0}+\left(N-N_{0}\right)
$$

Subtracting $N_{0}$ from both sides of Eq. (6), gives an equation for the change in population size:

$$
N-N_{0}=N_{0}\left(\mathrm{e}^{r_{\text {pop }} t}-1\right)
$$

which can be substituted into Eq. (A2):

$$
M=M_{0}+\left(N_{0}\left(\mathrm{e}^{r_{\mathrm{pop}} t}-1\right)\right)
$$

From the exponential growth rate equation, the growth rate of sightings off Los Angeles is:

$$
r_{\mathrm{LA}}=\frac{1}{t} \ln \frac{M}{M_{0}}
$$

Substituting Eq. (A4) for $M$ in Eq. (A5) results in:

$$
r_{\mathrm{LA}}=\frac{1}{t} \ln \frac{M_{0}+\left(N_{0}\left(\mathrm{e}^{r_{\mathrm{pop}} t}-1\right)\right)}{M_{0}}
$$

If, for example, we assume $1 / 10$ of the population migrates along the coast at Los Angeles at the start of the time series or $M_{0} / N_{0}=0.1$ and let $t=7 \mathrm{yr}$ and $r_{\text {pop }}=5.20 \% \mathrm{yr}^{-1}$, then the growth rate in sightings off Los Angeles, $r_{\mathrm{LA}}$, would equal $24 \% \mathrm{yr}^{-1}$, which is close to the measured growth rate of sightings off Los Angeles $\left(25.6 \% \mathrm{yr}^{-1}\right)$. Keeping all these assumptions, if the proportion of the total population using the coastal route at the start of the time series is less than the assumed $1 / 10$, the growth rate of number of whales off Los Angeles would be even greater. The fraction of the population using the coastal route seems reasonable based on aerial surveys (Carretta et al. 2000) but could be estimated more precisely after correcting the raw ACS/LA census sightings for probability of detection. Therefore, these equations support the hypothesis that the increase in the number of gray whales and proportion of the population taking the coastal route can be explained by the increasing population size.

Editorial responsibility: Peter Corkeron, Woods Hole, Massachusetts, USA
Submitted: November 26, 2018; Accepted: May 7, 2019

Proofs received from author(s): August 16, 2019 